\title{
VARIABILIDADES INTER E INTRAESPECÍFICA NA SUSCETIBILIDADE DE ÁCAROS FITOSEÍDEOS (ACARI: PHYTOSEIIDAE) A DICOFOL E DELTAMETRINA EM CITROS
}

MARCELO POLETTI

Dissertação apresentada à Escola Superior de Agricultura "Luiz de Queiroz", Universidade de São Paulo, para obtenção do título de Mestre em Ciências, Área de Concentração: Entomologia

PIRACICABA

Estado de São Paulo - Brasil

Maio - 2002 


\section{VARIABILIDADES INTER E INTRAESPECÍFICA NA SUSCETIBILIDADE DE ÁCAROS FITOSEÍDEOS (ACARI: PHYTOSEIIDAE) A DICOFOL E DELTAMETRINA EM CITROS}

\section{MARCELO POLETTI}

Engenheiro Agrônomo

Orientador: Prof. Dr. CELSO OMOTO

Dissertação apresentada à Escola Superior de Agricultura "Luiz de Queiroz", Universidade de São Paulo, para obtenção do título de Mestre em Ciências, Área de Concentração: Entomologia

PIRACICABA

Estado de São Paulo - Brasil

Maio - 2002 


\section{Dados Internacionais de Catalogação na Publicação (CIP)} DIVISÃO DE BIBLIOTECA E DOCUMENTAÇÃO - ESALQ/USP

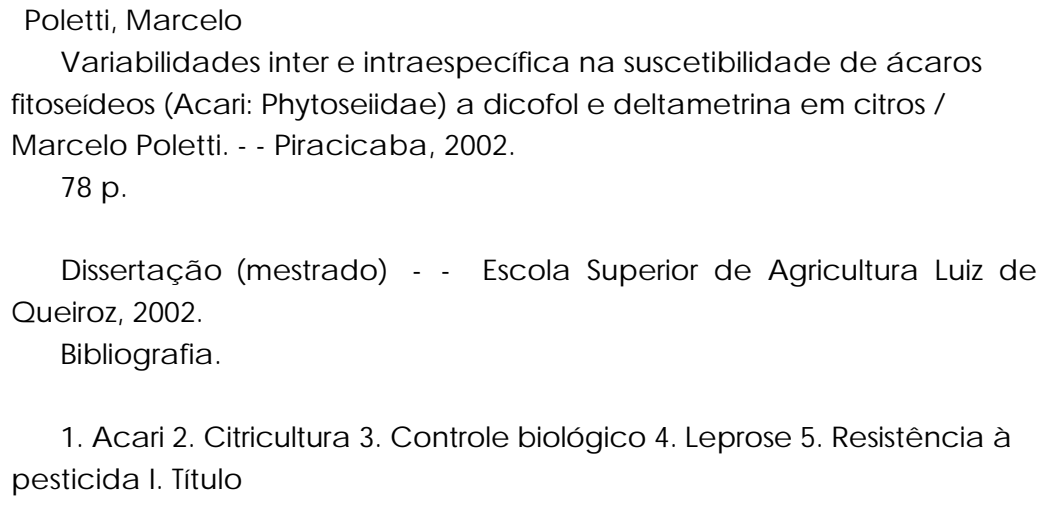

CDD 634.3

\section{"Permitida a cópia total ou parcial deste documento, desde que citada a fonte - $\mathrm{O}$ autor"}




\section{À DEUS \\ Fonte de força e equilíbrio \\ AGRADEÇO}

Aos meus pais ADILSON e RITA

e aos meus irmãos LÍLIAN e MAURÍCIO,

pelo afeto, compreensão e incentivo

DEDICO

À ELAINE CRISTINA CATAPANI

pelo amor e incentivo permanentes

OFEREÇO 


\section{AGRADECIMENTOS}

Ao Prof. Dr. Celso Omoto pela orientação, apoio, confiança e incentivo durante todo o percurso percorrido na execução deste trabalho.

Ao Prof Dr. Gilberto José de Moraes pela identificação de algumas populações de ácaros utilizadas neste trabalho.

Ao Dr. Mário Eidi Sato pela coleta de ácaros na Estação Experimental do Instituto Biológico em Presidente Prudente/SP e pelas valiosas informações concedidas.

A todos os professores do Programa de Pós-graduação em Entomologia da Escola Superior de Agricultura "Luiz de Queiroz"-ESALQ/USP, pelos conhecimentos e apoio transmitidos.

À Coordenação de Aperfeiçoamento de Pessoal de Nível Superior (CAPES) pela concessão da bolsa de estudos durante o período de realização do presente trabalho.

À Fischer Agropecuária S.A., pelo apoio e fornecimento de algumas populações de ácaros utilizadas neste trabalho.

Ao Fundo de Defesa da Citricultura - Fundecitrus, pelo apoio ao projeto. 
À colega Aloyséia Cristina da Silva Noronha, pelas sugestões e auxílios iniciais prestados.

Ao Biólogo Heraldo Negri de Oliveira pelas fotos dos ácaros predadores.

Aos amigos do "Laboratório de Resistência de Artrópodes à Pesticidas"ESALQ/USP, Cláudio Roberto Franco, Eloisa Salmeron, Everaldo Batista Alves, Fernando Joly Campos, Marina Regina Frizzas e Roberto Hiroyuki Konno pela amizade e colaboração.

Aos amigos Denise Návia, Diogo Carvalho, Enrique Castiglione, Jerson Carús Guedes, Jorge Anderson Guimarães, e Ricardo Antonio Polanczyk pelo companherismo e amizade demonstrada.

A todos os colegas e amigos do Setor de Entomologia pelo companherismo e incentivo.

À todas as pessoas que direta ou indiretamente contribuíram com o desenvolvimento deste trabalho. 


\section{SUMÁRIO}

\section{Página}

LISTA DE FIGURAS ........................................................................ ix

LISTA DE TABELAS................................................................ xi

RESUMO_.....................................................................................

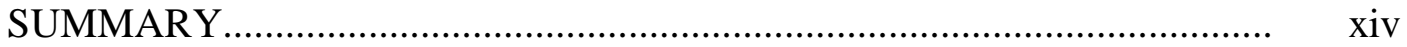

1 INTRODUÇÃO........................................................................... 1

2 REVISÃO DE LITERATURA....................................................... 3

2.1 Considerações gerais sobre os ácaros fitoseídeos................................... 3

2.1.1 Importância no controle biológico de ácaros fitófagos......................... 3

2.1.2 Aspectos taxonômicos..................................................................

2.1.3 Aspectos bioecológicos.................................................................... 4

2.1.4 Ocorrência e distribuição na cultura dos citros no Brasil..................... 6

2.1.5 Atividade predatória sobre o ácaro-da-leprose dos citros Brevipalpus phoenicis.............................................................................. 8

2.2 Integração dos controles químico e biológico para o manejo de ácaros... 9

2.2.1 Efeito de pesticidas sobre os ácaros fitoseídeos em citros.................. 10

2.2.1.1 Acaricidas............................................................................. $\quad 10$

2.2.1.2 Fungicidas.............................................................................. 11

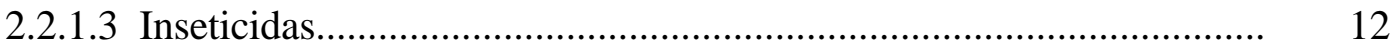

2.2.2 Evolução da resistência de ácaros fitoseídeos a pesticidas................... 14 
2.2.2.1 Resistência de fitoseídeos a inseticidas.

2.2.2.2 Liberação e estabelecimento de linhagens de fitoseídeos resistentes a inseticidas.

3 MATERIAL E MÉTODOS .............................................................. 20

3.1 Coleta de populações em campo.......................................................... 20

3.2 Criação estoque em condições de laboratório.......................................... 24

3.2.1 Amblyseius chiapensis e Euseius concordis...................................... 24

3.2.2 Iphiseiodes zuluagai.................................................................. 25

3.3 Avaliação das variabilidades inter e intraespecífica ao acaricida dicofol 26

3.3.1 Bioensaios toxicológicos............................................................... 26

3.3.1.1 Amblyseius chiapensis e Euseius concordis................................. 26

3.3.1.2 Iphiseiodes zuluagai............................................................... 27

3.3.1.3 Caracterização da linha básica de suscetibilidade.............................. 27

3.4 Avaliação da variabilidade interespecífica de Euseius concordis e Iphiseiodes zuluagai à deltametrina......................................... 28

3.4.1 Bioensaios toxicológicos............................................................. 28

3.4.2 Caracterização da linha básica de suscetibilidade................................ 29

3.5 Monitoramento da suscetibilidade de populações de Euseius concordis e Iphiseiodes zuluagai à deltametrina...

3.6 Avaliação da variabilidade intraespecífica de populações de Euseius concordis e Iphiseiodes zuluagai à deltametrina..................... 31

3.6.1 Caracterização toxicológica.............................................................. 31

3.7 Avaliação da variabilidade nas respostas de repelência à deltametrina nas populações Ec-1 e Ec-3 de Euseius concordis............................. 32

4 RESULTADOS E DISCUSSÃO.................................................... 34

4.1 Avaliação das variabilidades inter e intraespecífica ao acaricida dicofol. $\quad 34$

4.2 Avaliação da variabilidade interespecífica de Euseius concordis

e Iphiseiodes zuluagai à deltametrina................................................ 38

4.3 Monitoramento da suscetibilidade de populações de Euseius concordis e Iphiseiodes zuluagai à deltametrina. 
4.4 Avaliação da variabilidade intraespecífica de populações de

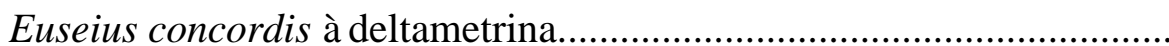

4.5 Avaliação da variabilidade intraespecífica de populações de Iphiseiodes zuluagai à deltametrina................................................... 51

4.6 Avaliação da variabilidade nas respostas de repelência à deltametrina nas populações Ec-1 e Ec-3 de Euseius concordis............................. 55

4.7 Considerações finais................................................................... 58

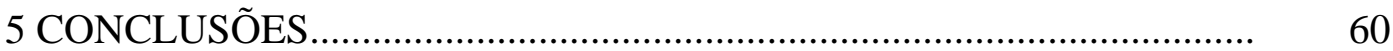

REFERÊNCIAS BIBLIOGRÁFICAS.................................................... 61 


\section{LISTA DE FIGURAS}

Página

1 Espécies de ácaros fitoseídeos. (A) Amblyseius chiapensis DeLeon; (B) Euseius concordis (Chant), (C) Iphiseiodes zuluagai

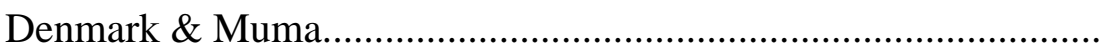

2 (A, B) Arenas utilizadas nos bioensaios realizados para a avaliação da suscetibilidade de Amblyseius chiapensis, Euseius concordis e Iphiseiodes zuluagai ao dicofol. (C) Arena utilizada nos bioensaios realizados para a avaliação da suscetibilidade de Euseius concordis e Iphiseoides zuluagai à deltametrina. (D) Arena utilizada nos bioensaios realizados para avaliar a variabilidade nas respostas de repelência à deltametrina nas populações Ec-1 e Ec-3 de Euseius concordis.

3 Curvas de concentração-mortalidade de Euseius concordis (Ec-1) e Iphiseiodes zuluagai (Iz-1) à deltametrina.

4 Porcentagem de sobrevivência de diferentes populações de Iphiseiodes zuluagai e Euseius concordis em bioensaios para o monitoramento da suscetibilidade na concentração diagnóstica de $10 \mathrm{mg}$ de deltametrina/L de água destilada. 
5 Curvas de concentração-mortalidade das populações Ec-1 e Ec-3 de Euseius concordis à deltametrina.................................................. 50

6 Curvas de concentração-mortalidade das populações Iz-1 e Iz-4 de Iphiseiodes zuluagai à deltametrina ................................................ 54

7 Curvas de concentração-repelência das populações suscetível (Ec-1) e Ec-3 de Euseius concordis à deltametrina........................... 57 


\section{LISTA DE TABELAS}

Página

1 Respostas de concentração-mortalidade de Amblyseius chiapensis,

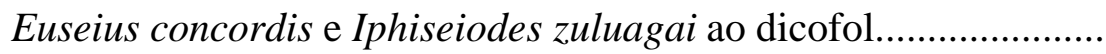

2 Respostas de concentração-mortalidade das populações Ec-1, Ec-2 e Ec-3 de Euseius concordis ao dicofol.........................................

3 Respostas de concentração-mortalidade de Euseius concordis e Iphiseiodes zuluagai à deltametrina...............................................

4 Respostas de concentração-mortalidade das populações Ec-1, Ec-2

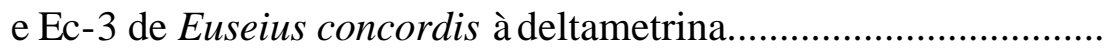

5 Respostas de concentração-mortalidade das populações Iz-1, Iz-3, Iz-4 e Iz-6 de Iphiseiodes zuluagai à deltametrina.

6 Respostas de concentração-repelência das populações Ec-1 e Ec-3 de Euseius concordis à deltametrina... 


\title{
VARIABILIDADES INTER E INTRAESPECÍFICA NA SUSCETIBILIDADE DE ÁCAROS FITOSEÍDEOS (ACARI: PHYTOSEIIDAE) A DICOFOL E DELTAMETRINA EM CITROS
}

\author{
Autor: MARCELO POLETTI \\ Orientador: Prof. Dr. CELSO OMOTO
}

\section{RESUMO}

A crescente utilização do controle químico para o manejo de pragas na cultura dos citros tem afetado significativamente a dinâmica populacional de inimigos naturais como os ácaros predadores que são importantes no controle biológico de pragas como o ácaro-da-leprose Brevipalpus phoenicis (Geijskes). Dentro desse contexto, a integração dos controles químico e biológico, seja pela utilização de produtos seletivos ou linhagens de ácaros predadores resistentes a pesticidas, poderia resultar em uma forma de manejo racional de ácaros fitófagos. Sendo assim, a presente pesquisa foi desenvolvida para avaliar a suscetibilidade de diferentes espécies de ácaros fitoseídeos (Amblyseius chiapensis De Leon, Euseius concordis (Chant) e Iphiseiodes zuluagai Denamark \& Muma) a dicofol e deltametrina, em populações coletadas em pomares de citros. Não houve variabilidade interespecífica na suscetibilidade ao dicofol. E também, não foi constatada variabilidade intraespecífica na suscetibilidade das populações de E. concordis testadas. Por outro lado, E. concordis apresentou-se 
aproximadamente 50 vezes mais tolerante do que I. zuluagai à deltametrina. Foi detectada variabilidade intraespecífica na suscetibilidade à deltametrina nas populações de E. concordis e I. zuluagai, sendo que a razão de resistência estimada foi maior do que 14 vezes para as populações de E. concordis e de 18 vezes para as populações de I. zuluagai testadas. E por último, verificou-se diferenças significativas quanto a respostas de repelência apresentadas pelas populações de E. concordis a resíduos de deltametrina. 


\title{
INTER AND INTRAESPECIFIC VARIABILITIES IN THE SUSCEPTIBILITY TO DICOFOL AND DELTAMETHRIN IN PHYTOSEIID MITES (ACARI: PHYTOSEIIDAE) IN CITRUS
}

\author{
Author: MARCELO POLETTI \\ Adviser: Prof. Dr. CELSO OMOTO
}

\section{SUMMARY}

The increase in the use of chemical control for managing pests of citrus has significantly affected the population dynamics of natural enemies such as predator mites that are important in the biological control of phytophagous mites such as Brevipalpus phoenicis (Geijskes). Within this context, the integration of chemical and biological control through the use of selective pesticides or strains of predator mites resistant to pesticides could be a more rational way to manage phytophagous mites. Thus, the objective of this research was to evaluate the susceptibility to dicofol and deltamethrin in populations of different phytoseiid species Amblyseius chiapensis DeLeon, Euseius concordis (Chant) e Iphiseiodes zuluagai Denamark \& Muma) collected in citrus groves. There was no interespecific variability in response to dicofol. And also, no intraespecific variability in the susceptibility to dicofol in E. concordis populations was detected in this study. On the other hand, E. concordis was 50 times more tolerant than I. zuluagai to deltamethrin. Intraespecific variability in the susceptibility to deltamethrin 
was detected for both E. concordis and I. zuluagai populations. A resistance ratio of >14-fold and 18-fold was detected to deltamethrin in E. concordis and I. zuluagai populations, respectively. And finally, there was a significant difference in the repellency of E. concordis populations in deltamethrin residues. 


\section{INTRODUÇÃO}

A citricultura paulista é responsável por cerca de $83 \%$ da produção brasileira de laranja, que foi de aproximadamente 18 milhões de toneladas em 2001 (FNP Consultoria \& Comércio, 2002). Dentre os fatores limitantes na cultura dos citros, o controle de pragas (insetos e ácaros) é tido como um dos principais. Um acréscimo de aproximadamente 7,5\% nos gastos com inseticidas foi observado entre os anos de 1997 e 1999 (Neves et al., 2001), principalmente devido ao emprego de produtos como piretróides e organofosforados para o controle de cigarrinhas (Hemiptera: Cicadellidae, Cicadellinae), larva-minadora-dos-citros (Phyllocnistis citrella Stainton) e bicho-furão (Ecdytolopha aurantiana (Lima)) (Gravena, 1997). Além disso, estima-se que aproximadamente 70 milhões de dólares foram gastos em 1999 com acaricidas na citricultura brasileira (Neves et al., 2001) para o controle do ácaro-da-leprose Brevipalpus phoenicis (Geijskes) (Acari: Tenuipalpidae), transmissor da doença conhecida como leprose dos citros, apontada como um dos principais fatores para a redução da produtividade de laranja no Estado de São Paulo (Guirado \& Silverio, 1992).

Dessa forma, a freqüente utilização de inseticidas de largo espectro de ação e acaricidas não seletivos, têm causado sérios problemas à citricultura como por exemplo: resistência de insetos e ácaros, ressurgência de pragas, além de um intenso desequilíbrio ecológico. Assim, as falhas observadas no controle do ácaro-da-leprose em citros, podem estar sendo agravadas devido à interferência drástica de alguns produtos químicos sobre a densidade populacional dos ácaros predadores fitoseídeos (Gravena, 1990), importantes inimigos naturais dessa praga (Moraes \& Sá, 1995). Quanto a esses ácaros, as principais espécies encontradas nos pomares paulistas são 
Euseius citrifolius Denmark \& Muma, Euseius concordis (Chant) e Iphiseiodes zuluagai Denmark \& Muma (Sato et al., 1994).

A preservação e o aumento na densidade populacional dos inimigos naturais podem ser importantes estratégias dentro do manejo de ácaros nessa cultura. Em um aspecto mais amplo, a combinação de táticas de controle como o químico e o biológico, pode resultar em uma forma de manejo mais racional. Dessa forma, deve-se observar o efeito do controle químico, não somente sobre a interação planta $\times$ praga, mas também sobre o terceiro nível trófico (Wright \& Verkerk, 1995). Com o intuito de realizar a integração desses métodos de controle para o manejo de ácaros, tem sido recomendado o uso de produtos seletivos aos inimigos naturais e a utilização de linhagens de ácaros predadores resistentes a produtos de largo espectro de ação.

Com relação à seletividade, vários trabalhos têm sido realizados visando avaliar o efeito dos principais produtos químicos utilizados na citricultura brasileira sobre os ácaros fitoseídeos (Komatsu \& Nakano, 1988; Yamamoto et al., 1992; Moreira et al., 1993; Sato et al., 1995; Raga et al., 1997; Reis et al., 1999). No entanto, no que se refere à seleção de ácaros predadores resistentes a pesticidas, nenhuma referência consta na literatura citrícola brasileira até o presente momento, ao contrário do que ocorre em outros países em culturas como a da amêndoa (Hoy, 1985a), citros (Kennett, 1970; Tanigoshi \& Fargerlund, 1984), chá (Mochizuki, 1994; Sato et al., 2000), maçã (Bloomers, 1994; Hardman et al., 2000; Marshall et al., 2001) entre outras.

Devido à carência de estudos nesta área, a presente pesquisa foi desenvolvida tendo como principal objetivo a avaliação da suscetibilidade ao dicofol e à deltametrina em diferentes espécies e populações de ácaros fitoseídeos coletadas em pomares de citros, com o intuito de contribuir com subsídios para o manejo racional do ácaro-daleprose nessa cultura. Para tanto foram avaliadas a variabilidade interespecífica de Amblyseius chiapensis DeLeon, E. concordis e I. zuluagai ao dicofol, e de E. concordis e I. zuluagai à deltametrina. Posteriormente, procedeutse à avaliação da variabilidade intraespecífica de E. concordis ao dicofol e de E. concordis e I. zuluagai à deltametrina. E por último, avaliourse a variabilidade nas respostas de repelência à deltametrina em duas populações de E. concordis. 


\section{REVISÃO DE LITERATURA}

\subsection{Considerações gerais sobre os ácaros fitoseídeos}

\subsubsection{Importância no controle biológico de ácaros fitófagos}

Os ácaros predadores são considerados os inimigos naturais mais efetivos no controle biológico dos ácaros fitófagos, sendo que as famílias que incluem espécies predadoras são: Anystidae, Bdellidae, Cheyletidae, Cunaxidae, Phytoseiidae e Stigmaeidae (Moraes, 1991; Yaninek \& Moraes, 1991). Dentre esses, os fitoseídeos são considerados os mais importantes e conhecidos, apresentando mais de 1700 espécies descritas mundialmente (Kostiainen \& Hoy, 1996), das quais aproximadamente 100 já foram observadas no Brasil (Moraes, 1992).

Devido ao elevado potencial desses agentes do controle biológico, algumas espécies vêm sendo estudadas em diferentes países, observando-se que em alguns, a utilização dos mesmos em programas de manejo de ácaros fitófagos apresenta-se em um estágio bastante avançado, empregando-se inclusive, linhagens resistentes a pesticidas (Hoy, 1985a; Solomon et al., 1993; Blommers, 1994; Hardman et al., 2000).

Ressalta-se que muitas espécies ainda não estudadas podem apresentar um grande potencial para aplicação prática em diferentes culturas. Nesse caso, primeiramente recomenda-se realizar estudos sobre sua eficiência, para uma subseqüente implementação de programas de transferência desses organismos para novas áreas onde possam atuar integrando o manejo de pragas de uma determinada cultura (Moraes, 2000). 


\subsubsection{Aspectos taxonômicos}

Os fitoseídeos pertencem à subordem Gamasida, superfamília Phytoseioidea, classe Arachnida e subclasse Acari. As principais espécies que ocorrem associadas à cultura dos citros no Estado de São Paulo, compõem à subfamília Amblyseiinae, sendo que as mesmas foram caracterizadas taxonomicamente por Lofego (1998) e Moraes (1986).

Os fitoseídeos são raramente maiores do que $5 \mathrm{~mm}$ quando adultos. Possuem o corpo dividido em duas regiões denominadas idiossoma onde localizam-se as pernas, e gnatossoma, que entre outras estruturas, abrigam um par de palpos com funções sensoriais e um par de quelíceras que auxiliam na captura da presa.

Caracterizam-se por apresentar nos estágios de deutoninfa e adulto um único escudo dorsal, o qual possui um número máximo de 20 pares de setas. Nas pernas podem ser evidenciadas estruturas denominadas "macrosetas", que apresentam um tamanho significativamente maior do que as demais setas presentes nesse apêndice (Chant, 1985a).

\subsubsection{Aspectos bioecológicos}

Os fitoseídeos movem-se de maneira mais rápida do que suas presas e apresentam um aspecto brilhante quando vivos (Chant, 1985b). Apresentam cinco estágios de desenvolvimento: ovo, larva, protoninfa, deutoninfa e adulto (Chant, 1985a), com curtos períodos de quiescência entre os mesmos (Sanderson \& McMurtry, 1984). Possuem um ciclo de vida curto, sendo que a maioria das espécies completa o desenvolvimento de ovo a adulto em aproximadamente uma semana (Hoy, 1985b).

O período de incubação pode variar com a umidade relativa do ar (McMurtry \& Scriven, 1965), temperatura (Moraes \& McMurtry, 1981), espécie considerada (Rasmy \& El-Banhawy, 1975) e tipo de alimento ingerido (Furtado \& Moraes, 1998).

A maioria das espécies inseridas nessa família apresenta um modo de reprodução denominado pseudo-arrenotoquia (o qual assemelha-se muito à arrenotoquia 
que ocorre por exemplo nos ácaros tetraniquídeos) (Schulten, 1985). Na pseudoarrenotoquia, machos e fêmeas são originários de ovos diplóides (2n) fecundados, no entanto, algumas horas após a fecundação, ocorre a perda de um conjunto de cromossomos de origem paterna em alguns ovos, os quais darão origem a machos haplóides (n), que apresentam basicamente a mesma constituição genética materna (Hoy, 1985b).

As fêmeas ovipositam em média dois ovos por dia, podendo colocar de 30 a 60 ovos durante o período de vida, dependendo da espécie e fonte de alimento dentre outros fatores (Jeppson et al., 1975). Yamamoto \& Gravena (1996) determinaram que para Iphiseiodes zuluagai Denmark \& Muma, a fecundidade média total (ovos/fêmea) e diária (ovos/fêmea/dia) foram de 36,7 e 1,5 e 34,9 e 1,2 para indivíduos alimentados com pólen de mamona, Ricinus comunis L., e pólen de taboa, Typha angustifolia L. respectivamente. Já o período de oviposição pode variar de 15 a 30 dias (Sabelis, 1985a).

Com relação à razão sexual, Reis \& Alves (1997) observaram que para Euseius alatus DeLeon a mesma foi de aproximadamente 0,6, observando-se uma proporção de 1,3 fêmeas para cada macho. No entanto, valores para razão sexual variando de 0,4 a 0,9 para 30 espécies de fitoseídeos em experimentos conduzidos à temperatura de $25^{\circ} \mathrm{C}$ foram citados por Sabelis (1985b).

No que diz respeito aos parâmetros biológicos, Sabelis (1985a) constatou que para 14 espécies de fitoseídeos alimentados com Tetranychus urticae Kock em condições laboratoriais, ocorreram amplas variações nos valores da taxa líquida de reprodução $\left(R_{0}\right)$, tempo para duração de uma geração $(T)$, capacidade intrínseca de crescimento da população $\left(\mathrm{r}_{\mathrm{m}}\right)$ e razão finita de aumento $(\lambda)$, afirmando que vários estudos têm demostrado amplas variações em relação a esse parâmetro, inclusive para diferentes populações de uma mesma espécie.

Um outro fator importante a ser considerado é o comportamento de dispersão e a mobilidade desses ácaros, principalmente quando o propósito dos estudos é a liberação em programas de controle biológico. Croft \& Dunley (1993) demonstraram que apesar de Metaseiulus occidentalis (Nesbitt) dispersar mais rapidamente dentro de uma mesma 
área e para distâncias mais longas do que Typhlodromus pyri Scheuten, esta espécie é mais comumente encontrada em pomares tratados com pesticidas. Por outro lado, T. pyri, por se tratar de uma espécie cosmopolita, pode ser encontrada tanto em pomares comerciais como em hospedeiros alternativos em campo.

Quanto à mobilidade, Hoy et al. (1984) observaram que M. occidentalis pode se movimentar caminhando de uma planta a outra, entretanto, por tratar-se de um ácaro de tamanho reduzido, as distâncias por ele percorridas são relativamente pequenas. Esses autores também verificaram que as fêmeas adultas em estado de inanição apresentaram comportamento explícito de dispersão em condições de laboratório.

\subsubsection{Ocorrência e distribuição na cultura dos citros no Brasil}

Os fitoseídeos foram os ácaros predadores encontrados com maior freqüência por Moreira (1993) em pomares situados em Jaboticabal/SP, sendo as seguintes espécies amostradas: I. zuluagai, Euseius citrifolius Denmark \& Muma, Typhlodromina camelliae (Chant \& Yoshiba Shaul), Amblydromella applegum (Schicha) e Amblyseiella setosa Muma, observando que a ocorrência desses ácaros deu-se principalmente nos meses de janeiro, fevereiro e de julho a setembro. I. zuluagai foi a espécie predominante, representando cerca de $85 \%$ dos ácaros amostrados.

Sato et al. (1994), através de levantamentos realizados em um pomar não comercial de citros em Presidente Prudente/SP, observaram a presença de seis espécies de ácaros fitoseídeos: I. zuluagai, E. citrifolius, E. concordis, E. alatus, Amblyseius chiapensis DeLeon, T. camelliae, destacando-se as três primeiras como predominantes. Nesse estudo, I. zuluagai apresentou maior incidência nos meses de junho e julho, ou seja, nos meses em que ocorreram as menores médias de temperaturas registradas durante o experimento. Verificaram também, correlação negativa entre os níveis populacionais deste ácaro e a precipitação pluviométrica. Por outro lado, observaram que as populações de Euseius spp. apresentaram os maiores níveis populacionais de outubro a janeiro, não sendo averiguada a influência significativa da precipitação pluviométrica sobre a dinâmica populacional dessa espécie. 
Em Lavras/MG, Reis et al. (2000a) verificaram que as espécies de ácaros fitoseídeos mais abundantes em pomares de citros foram I. zuluagai e E. alatus, relatando também a presença de Amblyseius compositus Denmark \& Muma, Amblyseius herbicolus (Chant) e Phytoseiulus macropilis (Banks). Nessas condições, I. zuluagai apresentou maior densidade populacional entre os meses de abril e setembro, período de temperaturas amenas e baixa precipitação pluvial. De modo contrário, para E. alatus, os picos populacionais ocorreram entre os meses de outubro e fevereiro, período de temperaturas mais elevadas e alta precipitação pluvial. Ainda segundo esses autores, o fato das espécies E. citrifolius e E. concordis, comumente relatadas na cultura dos citros, não terem sido observadas nesse estudo, pode ter sido reflexo tanto das condições climáticas da região quanto do manejo local adotado para a cultura.

Em Piracicaba/SP, Rodrigues (2000) verificou que I. zuluagai apresentou os maiores níveis populacionais entre os meses de abril e junho. Foi observada que essa espécie ocorreu associada ao ácaro B. phoenicis, principalmente nas folhas com injúrias causadas por Phyllocnistis citrella Stainton.

Deve-se ressaltar que a ocorrência de espécies de fitoseídeos em pomares de citros no Brasil varia de acordo com a região considerada. Por exemplo, a espécie I. zuluagai, comumente encontrada na região Sudeste geralmente associada ao ácaro-da-leprose, nunca foi observada atacando o mesmo na região Nordeste do país (Moraes \& Sá, 1995).

Quanto à distribuição espacial dos ácaros predadores na planta de citros, Gravena (1991) citou que E. citrifolius e I. zuluagai foram facilmente localizados em folhas grandes e internas da copa, ao longo da nervura da face inferior. Raga et al. (1996) relataram a ocorrência desses ácaros nos terços médio e inferior da copa, principalmente sob teias de insetos da ordem Psocoptera. 


\subsubsection{Atividade predatória sobre o ácaro-da-leprose dos citros Brevipalpus phoenicis}

Vários trabalhos têm demonstrado a capacidade de predação de algumas espécies de fitoseídeos sobre o ácaro-da-leprose dos citros no Brasil. Em condições de laboratório, Komatsu \& Nakano (1988) destacaram o estágio adulto de E. concordis como o mais eficiente sobre essa presa, ocorrendo maior consumo sobre ovos e formas jovens do ácaro-da-leprose.

Avaliando a atividade predatória de E. citrifolius sobre B. phoenicis, Gravena et al. (1994) observaram que as fases mais efetivas desse predador foram larva, ninfa e fêmea adulta. Com relação à presa, a fase mais consumida foi a de larva e o aumento da relação predador:presa resultou em aumento na atividade predatória. Verificaram também que a presença de verrugose nos frutos causou uma redução significativa na predação.

A predação de $I$. zuluagai e E. alatus sobre B. phoenicis foi avaliada por Reis et al. (2000b). O estágio do ácaro-da-leprose mais suscetível ao ataque desses inimigos naturais foi o de larva, seguido por ovo e ninfa, e os estágios mais agressivos do predador foram o de fêmea adulta e ninfa. Comparando a atividade predatória dessas duas espécies, os autores observaram que I. zuluagai foi a mais efetiva, consumindo em média $90 \%$ de larva, $83 \%$ de ovos, $77 \%$ de ninfas e $18 \%$ de adultos. Deve-se ressaltar que em geral os ácaros predadores com hábito generalista preferem alimentar de larvas porém, existem espécies que predam indistintamente qualquer estágio de desenvolvimento da presa (Blackwood et al., 2001).

A capacidade predatória de A. chiapensis sobre o ácaro-da-leprose dos citros foi avaliada por Poletti et al. (2001). Esses autores verificaram que essa espécie foi eficiente no consumo da presa, e que apesar de ocorrer em baixos níveis populacionais em campo (Sato et al., 1994), pode estar atuando em conjunto com outras espécies de fitoseídeos no controle biológico do ácaro B. phoenicis. 


\subsection{Integração dos controles químico e biológico para o manejo de ácaros}

$\mathrm{Na}$ maioria dos programas de manejo integrado de pragas (MIP), o controle químico se constitui na tática mais explorada, o que muitas vezes tem inviabilizado o desempenho de outras como o controle biológico. Além desse fato, a utilização excessiva do controle químico tem sido responsável por causar desequilíbrios ecológicos, ressurgência de pragas, incremento nos custos de produção e resistência de insetos e ácaros a pesticidas.

Porém, a tendência atual do MIP é proporcionar um equilíbrio ecológico entre as pragas e seus inimigos naturais (Kogan, 1998), sendo importante desenvolver técnicas que favoreçam esse fato. Com relação ao manejo de ácaros, duas alternativas têm sido recomendadas como forma de integrar os controles químico e biológico. A primeira refere-se à utilização de produtos seletivos, e a segunda à detecção, seleção e liberação de ácaros predadores resistentes a produtos de largo espectro de ação como os piretróides e organofosforados (Croft \& Barnes, 1972).

$\mathrm{Na}$ citricultura brasileira, somente a primeira alternativa tem sido utilizada. No entanto, com intuito de rotacionar os grupos químicos utilizados (Gravena, 1994), impedindo dessa forma o aumento da freqüência de pragas resistentes, já que essa consta de uma das táticas recomendadas para o manejo desse problema (Georghiou, 1983), inevitavelmente têm-se utilizado produtos nocivos aos inimigos naturais.

Quanto à utilização de ácaros predadores resistentes a pesticidas em culturas como amêndoa na Califórnia (Hoy, 1985a) e maçã em diversos países da Europa (Blommers, 1994), o emprego de tais organismos no manejo integrado tem sido constante. 


\subsubsection{Efeito de pesticidas sobre os ácaros fitoseídeos em citros}

Com o intuito de preservar os agentes do controle biológico e a utilização do controle químico para o manejo de B. phoenicis, são frequentes os trabalhos que visam avaliar o efeito dos pesticidas sobre os ácaros fitoseídeos.

\subsubsection{Acaricidas}

Produtos como dicofol e propargite têm sido considerados nocivos a E. alatus, E. concordis e I. zuluagai (Komatsu \& Nakano, 1988; Reis et al., 1998b; Reis et al., 1999). No entanto, apesar do dicofol exercer efeito negativo sobre esses predadores, esse acaricida tem sido considerado inócuo a alguns artrópodes benéficos presentes nessa cultura. Papa et al. (1991) avaliando a ação de alguns acaricidas sobre insetos predadores

e aranhas, observaram que esse produto apresentou pouco efeito sobre esses agentes do controle biológico, comprovando a eficiência do mesmo como acaricida específico. Considerando esse fato, e somando-o ao baixo custo de aquisição do dicofol, verifica-se que esse produto destaca-se como um dos acaricidas mais utilizados na cultura dos citros, principalmente onde a freqüência de ácaros resistentes é baixa (Omoto et al., 2000).

Os piretróides acrinatrina, bifentrina e fenpropatrina demonstraram elevada toxicidade a fitoseídeos (Komatsu \& Nakano, 1988; Yamamoto et al., 1992; Sato et al., 1994, 1995; Chiaradia \& Cruz, 1997; Reis et. al, 1998b, 1999). De acordo com Moreira et al. (1993), a bifentrina apresentou efeito de choque sobre I. zuluagai com significativa redução populacional, 24 horas após a aplicação em campo. Sato et al. (1996) verificaram que além da elevada toxicidade de bifentrina e fenpropatrina sobre I. zuluagai, esses produtos apresentaram um longo período residual de 38 e 45 dias respectivamente.

Quanto ao efeito dos acaricidas cihexatin e óxido de fenbutatin (pertencentes ao grupo químico dos organoestânicos) sobre os ácaros fitoseídeos, os dados não são consistentes na literatura. Cihexatin foi considerado nocivo a várias espécies de ácaros 
predadores, tanto em condições de laboratório (Komatsu \& Nakano, 1988; Reis et al., 1998b,1999) quanto em campo (Sato et al., 1992; Yamamoto et al., 1992; Sato et al., 1995; Santos \& Gravena, 1997). Chiaradia \& Cruz (1997) observaram que apesar desse produto ter interferido significativamente na densidade populacional inicial de I. zuluagai, permitiu um rápido restabelecimento da mesma em campo, sugerindo uma baixa ação residual tóxica. Quanto ao óxido de fenbutatin apesar de ter sido considerado nocivo a Amblyseius sp., E. citrifolius, E. concordis e I. zuluagai em campo (Sato et al., 1995), em condições de laboratório foi considerado levemente nocivo a E. alatus (Reis et al., 1999) e inócuo a I. zuluagai (Reis et al., 1998b). Santos \& Gravena (1997) determinaram que esse produto apresentou um período residual de 14 dias sobre esses predadores.

De acordo com Jacobson et al. (1999), os organoestânicos não possuem ação ovicida, o que pôde ser evidenciado por Reis \& Sousa (2001) quando avaliaram o efeito de óxido de fenbutatin sobre ovos de E. alatus.

Por outro lado, produtos como o hexitiazox (grupo químico das carboxamidas) e o abamectin (grupo químico das avermectinas) foram considerados inócuos ou levemente nocivos aos ácaros predadores em condições de campo (Sato et al., 1992, 1995; Raga et al., 1997) e laboratório (Hoy \& Ouyang, 1986; Komatsu \& Nakano, 1988; Reis et al., 1998b, 1999), sendo portanto produtos importantes para a preservação desses agentes do controle biológico nessa cultura.

\subsubsection{Fungicidas}

$\mathrm{O}$ efeito de alguns fungicidas também tem sido maléfico sobre ácaros fitoseídeos. O enxofre, utilizado geralmente como acaricida-fungicida, foi considerado moderadamente nocivo a Euseius sp. e Iphiseiodes sp. em condições de campo (Santos

\& Gravena, 1993, 1995), apresentando um período residual de até 58 dias (Sato et al., 1995). Em laboratório também foi observado que o mesmo exerceu uma ação não seletiva a I. zuluagai (Reis et al., 1998b) e E. alatus (Reis et al., 1999). 
De modo contrário, Silva (1980) detectou baixa toxicidade do enxofre a Iphiseiodes quadripilis (Banks) em condições de campo, sendo que a mesma observação foi feita por Komatsu \& Nakano (1988) sobre E. concordis em laboratório e por Chiaradia \& Cruz (1997) sobre I. zuluagai em campo. Dessa forma, esses autores recomendaram a utilização do enxofre dentro de um programa de manejo do ácaro-daleprose devido à seletividade apresentada.

Outros produtos como o benomyl e captan têm sido considerados prejudiciais aos ácaros predadores fitoseídeos, tanto em citros como em outras culturas. Por exemplo, o benomyl foi considerado nocivo a I. zuluagai (Reis et al., 1998b) e moderadamente nocivo a E. alatus (Reis et al., 1999). Hardman et al. (1991) verificaram que em pomares comerciais de maçã, tanto o benomyl quanto captan mostraram-se tóxicos a $T$. pyri, fato esse que contribuiu para a redução da densidade populacional do mesmo, afetando o controle biológico do ácaro vermelho Panonychus ulmi Koch.

\subsubsection{Inseticidas}

Com relação a inseticidas, apesar de não existir um número significativo de trabalhos que visam avaliar o efeito desses produtos sobre os ácaros predadores, em outras culturas como a da maçã esses dados são publicados com freqüência.

A excessiva utilização de piretróides, organofosforados e carbamatos tem causado um significativo aumento na densidade populacional de ácaros fitófagos, devido ao efeito negativo desses produtos sobre os ácaros predadores (Hoyt et al., 1978; Van de Vrie, 1985; Hardman et al., 1988, 1991). Com relação aos piretróides, os mesmos não apresentam um efeito uniforme sobre os ácaros, ocorrendo tanto variações nas respostas apresentadas em termos de espécies como em relação ao produto utilizado. Nesse sentido, Penman \& Chapman (1988) relataram que a primeira geração desses produtos, tais como permetrina e fenvalerate exerciam um elevado efeito de indução no aumento da densidade populacional dos ácaros pragas, fato esse, que passou a ser menos intenso devido à introdução de produtos mais modernos tais como o fluvalinate. 
De acordo com Croft \& Whalon (1982), os inseticidas piretróides apresentam elevada toxicidade a várias espécies de ácaros fitoseídeos, sendo que esses geralmente são considerados mais suscetíveis a esses produtos do que suas presas. Roush and Hoy (1978) avaliando o efeito desses inseticidas sobre M. occidentalis, observaram que o mesmo apresentou uma suscetibilidade de 20 a 40 vezes maior a esses produtos do que a sua presa T. urticae, o que foi confirmado por Rock (1979) que concluiu que apesar dos inseticidas permetrina e fenvalerate apresentarem-se praticamente inócuos a $T$. urticae, os mesmos mostraram-se altamente tóxicos a Amblyseius fallacis (Garman).

Em pomares de maçã na Inglaterra, Aliniazee \& Cranham (1980) verificaram que as aplicações feitas com permetrina, cipermetrina, fenvalerate e deltametrina foram responsáveis pelo aumento na densidade populacional do ácaro vermelho $P$. ulmi devido à elevada toxicidade desses produtos ao ácaro predador $T$. pyri.

Rield \& Hoying (1983) verificaram que o inseticida fenvalerate apresentou um longo período residual em condições de campo, sendo mais tóxico a $M$. occidentalis do que à sua presa T. urticae. Em cultivo protegido de rosas, Malezieux et al. (1992) observaram que os inseticidas organofosforados e carbamatos apresentaram menor persistência do que os piretróides, tais como fenpropatrina e deltametrina, que apresentaram toxicidade residual de no mínimo 30 dias sobre Phytoseiulus persimilis Athias-Henriot nessas condições.

Segundo Hardman et al. (1991), a flutuação populacional de $P$. ulmi está intrinsecamente associada ao regime de pulverizações com inseticidas considerados tóxicos ao ácaro predador T. pyri tais como: dimetoato, cipermetrina, deltametrina entre outros. Em levantamentos de ácaros predadores em pomares comerciais de maçã no Canadá, Thistlewood (1991) verificou que nas áreas onde os inseticidas piretróides foram empregados para o controle de insetos tais como a minadora Phyllonorycter blacardella (Fabr.), os ácaros fitoseídeos foram menos abundantes quando comparado com o levantamento realizado em outras áreas onde não foi adotado tal regime de aplicação. 
Solomon et al. (1993) verificaram que os programas de manejo de Cydia pomonella (L.) baseados na utilização de inseticidas piretróides foram prejudiciais às linhagens de T. pyri resistentes a organofosforados, sendo necessário o aumento no uso de acaricidas para o manejo de $P$. ulmi em pomares de maçã no Reino Unido.

No Brasil, Monteiro (2001) avaliando o efeito de produtos fitossanitários utilizados para o controle de pragas na cultura da macieira em Vacaria/RS sobre Neoseiulus californicus (McGregor), verificou que os inseticidas azinfós metil, deltametrina e fention mostraram-se altamente nocivos, demonstrando um forte efeito de choque sobre a espécie estudada. Porém, de acordo com esse autor, esses resultados não podem ser extrapolados para outras regiões macieiras, pois dentre outros fatores, as respostas das diferentes populações dessa espécie podem variar de acordo com a pressão de seleção local.

\subsubsection{Evolução da resistência de ácaros fitoseídeos a pesticidas}

Até o final da década de 80, o número de casos de resistência documentados era de 504 espécies de insetos e ácaros a pelo menos uma classe de composto químico. Dentre essas, 56,1\% correspondiam a espécies de importância agrícola, 39,3\% de importância-médico veterinária e apenas 4,6\% de inimigos naturais (Georghiou \& Lagunes-Tejeda, 1991).

As hipóteses da pré-adaptação diferencial e da limitação do alimento têm sido apresentadas com o intuito de explicar essa baixa taxa de detecção da resistência para os agentes do controle biológico (Croft \& Morse, 1979). A hipótese da pré-adaptação diferencial se baseia no fato de que as pragas estão melhor pré-adaptadas a sobreviver à aplicação de produtos químicos do que seus inimigos naturais, devido à capacidade intrínseca das mesmas em lidar com estresses bioquímicos associados a suas fontes de alimento. Uma possível explicação é que essa habilidade foi desenvolvida durante a co-evolução da relação planta-hospedeira e inseto-praga, podendo ocorrer diferenças nos processos de destoxificações hidrolítica e oxidativa entre o grupo das pragas e dos inimigos naturais (Plapp \& Bull, 1978). 
Quanto à hipótese da limitação do alimento, a mesma sustenta-se no fato de que os inimigos naturais que sobreviveram à aplicação de um determinado produto, poderiam sofrer falta de alimento devido à baixa disponibilidade da presa. Dessa forma, os indivíduos sobreviventes não se reproduziriam com eficiência, ou então poderiam emigrar para áreas não tratadas ocorrendo consequientemente a diluição da resistência pelo cruzamento com indivíduos suscetíveis. Nesse caso, o princípio dessa hipótese é que a evolução da resistência nas espécies fitófagas deve preceder a evolução nos inimigos naturais (Baker \& Arbogast, 1995).

Com relação aos ácaros predadores fitoseídeos, alguns fatores intrínsecos já abordados, tais como o tipo e a capacidade de reprodução além da capacidade de dispersão e mobilidade, podem favorecer a evolução da resistência a pesticidas. Um outro fator positivo para o aumento na freqüência de indivíduos resistentes nesse grupo, é a existência de espécies que são capazes de se alimentar em outras fontes como pólen e exudatos de plantas, fungos e pequenos insetos (McMurtry, 1997), podendo sobreviver mesmo na ausência da presa.

\subsubsection{Resistência de fitoseídeos a inseticidas}

A resistência dos ácaros fitoseídeos a pesticidas vem sendo estudada desde o final da década de 60 (Sanford, 1967), sendo que as principais espécies pesquisadas até o presente momento são: A. fallacis, M. occidentalis, $P$. persimilis e $T$. pyri (Croft et al., 1976; Fournier et al., 1988; Hadam et al., 1986; Hardman et al., 2000; Solomon et al., 1993).

Hoyt (1969) realizou a primeira documentação de resistência a azinfós metil (organofosforado) em uma população de $M$. occidentalis coletada em pomares de maçã em Washington/EUA. Posteriormente, elevada resistência a paration foi detectada em populações de Amblyseius hibisci (Chant) (Kennett, 1970) e Euseius hibisci (Chant) (Tanigoshi \& Congdon, 1983), ambas coletadas em pomares de citros na Califórnia/EUA. 
Kostiainen \& Hoy (1994a) detectaram variabilidade intraespecífica a inseticidas organofosforados em Amblyseius finlandicus (Oudemans), importante predador de P. ulmi e ácaros eriofídeos em maçã na Finlândia. Os autores, evidenciaram que os valores estimados para $\mathrm{CL}_{50}$ na maioria das populações oriundas de pomares comerciais apresentaram-se cinco vezes superior ao valor obtido para linhagem suscetível. Também, verificaram que a resistência observada em algumas populações avaliadas, permaneceu estável mesmo na ausência de pressão de seleção (Konstiainen \& Hoy, 1994b).

Ainda com relação aos inseticidas organofosforados, Sato et al. (2000) realizando quatro pressões de seleção em laboratório com metidation, obtiveram um aumento de aproximadamente 21 vezes na razão de resistência de uma população de Amblyseius womersleyi Schicha (importante predador de Tetranychus kanzawai Kishida na cultura do chá no Japão) a esse produto.

Roush \& Hoy (1980) realizando de 15 a 19 pressões de seleção com carbaryl em condições de laboratório, selecionaram populações de $M$. occidentalis para resistência a esse produto. Posteriormente, estudos realizados em laboratório e casa-devegetação, mostraram que essa linhagem desenvolveu mais lentamente e apresentou menor fecundidade do que a população suscetível de referência (Roush \& Hoy, 1981a). Porém, bioensaios para determinar a estabilidade da resistência e a utilização dessa linhagem no controle de ácaros fitófagos em casa-de-vegetação, demonstraram a ausência de custo adaptativo desses indivíduos resistentes, e que a razão intrínseca de desenvolvimento para os mesmos foi superior à encontrada para a população suscetível (Roush \& Hoy, 1981b). Ainda com relação a essas populações, Roush \& Plapp (1982) verificaram que as mesmas apresentaram-se resistentes também a propoxur (inseticida carbamato).

A resistência dos ácaros fitoseídeos aos inseticidas piretróides utilizados para o controle de insetos-pragas também tem sido documentada com freqüência. De acordo com Hoy (1985b), a variabilidade nas respostas dos ácaros fitoseídeos a piretróides, bem como outros inseticidas de largo espectro de ação, relaciona-se com o histórico do número de pulverizações de pesticidas realizado em campo. Nesse sentido, Mochizuki 
(1994) avaliando a ocorrência da variabilidade intraespecífica a cipermetrina, permetrina, fenvalerate e fluvalinate em populações de A. womersleyi coletadas em diferentes áreas de cultivo de chá no Japão, concluiu que a resistência observada em uma dessas populações relacionourse com o número de aplicações desses produtos realizadas no campo com esses produtos.

Fitzgerald \& Solomon (1992) realizando bioensaios para determinar a resposta de populações de $A$. fallacis a deltametrina, relataram a ocorrência de uma linhagem, cuja razão de resistência obtida foi de proximadamente quatro vezes, sendo que de acordo com Thistlewood et al. (1992) esse fato pode ser atribuído à intensa pressão de seleção com inseticidas piretróides nas áreas onde procedeu-se a coleta dessa população. Ainda, para essa mesma espécie, Thistlewoood et al. (1995) verificaram que após 55 pressões de seleção com permetrina sobre uma determinada população, pôde-se evidenciar um aumento de 964 vezes na resistência da mesma a esse produto em condições de laboratório.

Da mesma maneira, Hoy \& Knop (1981) também selecionaram para resistência a permetrina em populações de $M$. occidentalis coletadas em pomares de maçã situados em Washington/EUA. Verificaram que após 18 pressões de seleção, ocorreu um aumento de aproximadamente dez vezes na $\mathrm{CL}_{50}$ estimada para essa população.

Além da variabilidade intraespecífica, diferenças na suscetibilidade aos produtos químicos têm sido observadas em espécies distintas. Por exemplo, Marwick (1986) em estudos para a detecção das variabilidades inter e intraespecífica de P. persimilis e $T$. pyri aos inseticidas cipermetrina, deltametrina e fenvalerate, observou que a primeira espécie apresentou suscetibilidade maior a esses três piretróides do que T. pyri. Com relação à deltametrina, a razão de tolerância observada para essas duas espécies chegou a aproximadamente 314 vezes, sendo que a CL50 obtida para $P$. persimilis foi cerca de 7.143 vezes inferior à concentração de campo recomendada para o controle de insetos-pragas. 


\subsubsection{Liberação e estabelecimento de linhagens de fitoseídeos resistentes a inseticidas}

Um dos critérios utilizados para determinar o sucesso do estabelecimento de populações de inimigos naturais liberadas em campo é a sobrevivência dos mesmos a aplicações de defensivos químicos (Hoy et al., 1983).

Strickler \& Croft $(1981,1982)$ estudando a variabilidade intraespecífica de 12 populações de $A$. fallacis observaram que duas dessas apresentaram resistência a elevadas concentrações de permetrina, e que após 12 pressões de seleção com esse produto em casa de vegetação, a razão de resistência (RR) chegou a 64 vezes. Assim, quando essas populações resistentes à permetrina foram liberadas em pomares comerciais de maçã, pôde-se evidenciar o sucesso no estabelecimento das mesmas.

Após selecionarem duas populações para resistência a piretróides em condições de casa de vegetação, Whalon \& Croft (1982) verificaram que ambas sobreviveram a aplicações de permetrina quando liberadas em um pomar comercial de maçã, porém só uma delas resistiu à aplicação de fenvalerate, sugerindo a presença de resistência cruzada de permetrina com esse produto.

Hoy et al. (1983) obtiveram sucesso na liberação e estabelecimento de linhagens resistentes de $M$. occidentalis a organofosforados e piretróides em pomares de maçã e pêra, sugerindo uma relação entre a densidade populacional da praga em campo e o estabelecimento das populações de fitoseídeos liberadas.

Em experimentos de campo realizados em pomares de maçã com diferentes regimes de pulverizações, Hardman et al. (1997, 2000) obtiveram sucesso na liberação de uma linhagem resistente a piretróides e organofosforados de T. pyri introduzida da Nova Zelândia. Dessa forma, os autores concluíram que esses organismos apresentaram potencial para serem utilizados em programas de manejo de ácaros nessa cultura.

Falhas no estabelecimento de uma população de A. fallacis resistente a permetrina em campo foi verificada por Croft \& Whalon (1983). Segundo esses autores, tal fato pode ter ocorrido devido a um grande fluxo de indivíduos suscetíveis para dentro das áreas onde foram realizadas essas liberações. Assim, devido a esse fato poderia ter 
ocorrido hibridação, o que fatalmente ocasionou redução na freqüência de resistência. Por outro lado, esses autores observaram que em laboratório a resistência permaneceu estável até a 25ำ geração nessa população, mesmo na ausência de pressão de seleção.

Em termos práticos, Hoy (1985a) propôs um programa de manejo de ácaros na cultura da amêndoa (Califórnia/EUA) baseado na utilização de populações de ácaros predadores resistentes a inseticidas, associados à utilização de acaricidas seletivos. Observoutse que esse programa foi amplamente aceito pelos produtores, os quais alcançaram benefícios, tais como a redução nos gastos com acaricidas e um controle de ácaros mais satisfatório do que aquele realizado somente com o uso de produtos químicos. 


\section{MATERIAL E MÉTODOS}

O presente trabalho foi desenvolvido no "Laboratório de Resistência de Artrópodes a Pesticidas" do Departamento de Entomologia, Fitopatologia e Zoologia Agrícola da Escola Superior de Agricultura "Luiz de Queiroz", Universidade de São Paulo, Piracicaba - SP, no período de março de 2000 a fevereiro de 2002.

\subsection{Coleta de populações em campo}

Para iniciar as colônias em laboratório, foram realizadas coletas de populações de Amblyseius chiapensis DeLeon Euseius concordis (Chant) e Iphiseiodes zuluagai Denmark \& Muma (Figura 1) em pomares de citros abandonados, onde não haviam sido realizadas aplicações de pesticidas por no mínimo três anos, e em pomares comerciais, cujo controle químico era freqüentemente adotado. A identificação dessas populações e seus respectivos dados de coleta encontram-se no Quadro 1. O número de pulverizações com inseticidas piretróides realizado nos pomares comerciais num período de cinco anos (1997-2001) encontra-se no Quadro 2. Quanto ao dicofol, o histórico de uso deste acaricida em pomares comerciais avaliados não foi fornecido pelos proprietários dos mesmos. 

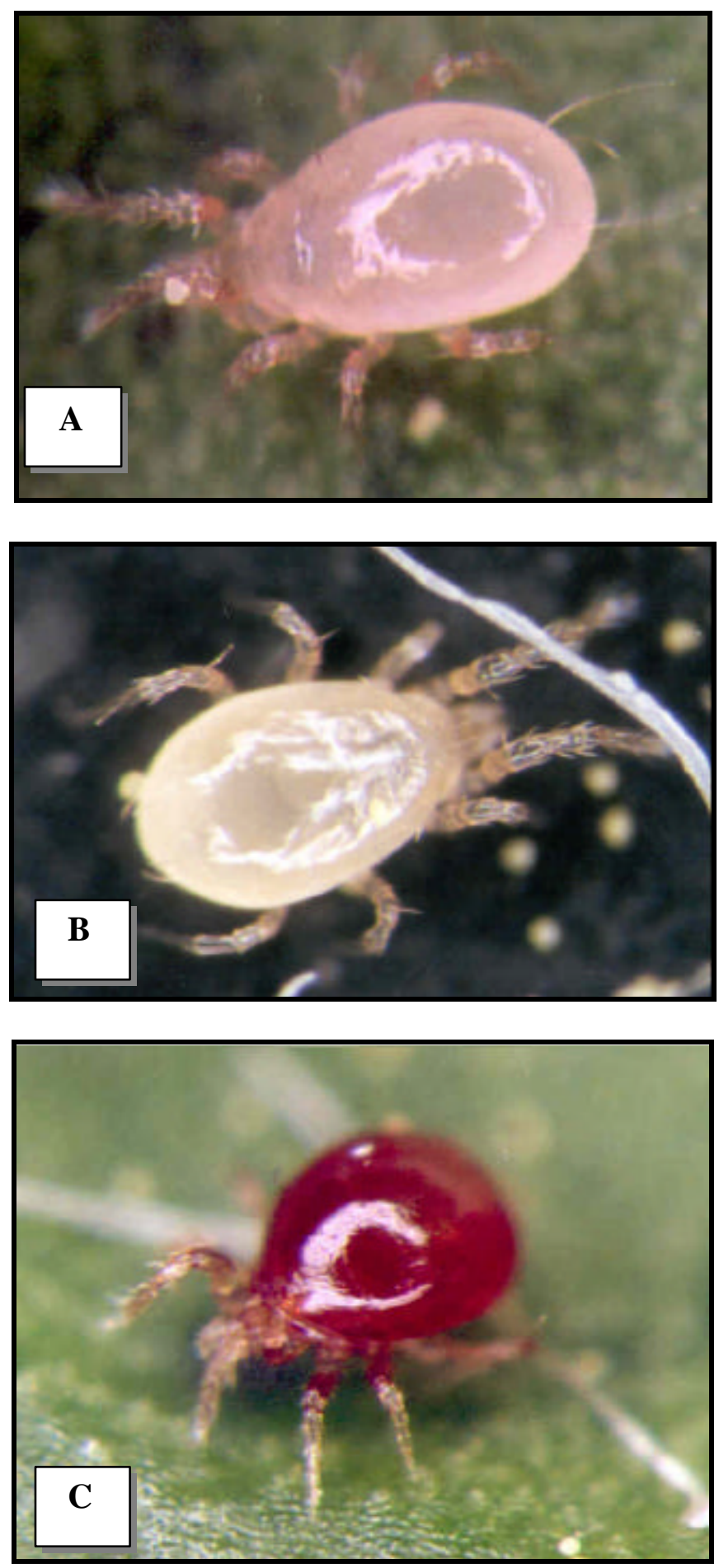

Figura 1 - Espécies de ácaros fitoseídeos. (A) Amblyseius chiapensis DeLeon; (B) Euseius concordis (Chant), (C) Iphiseiodes zuluagai Denmark \& Muma. 


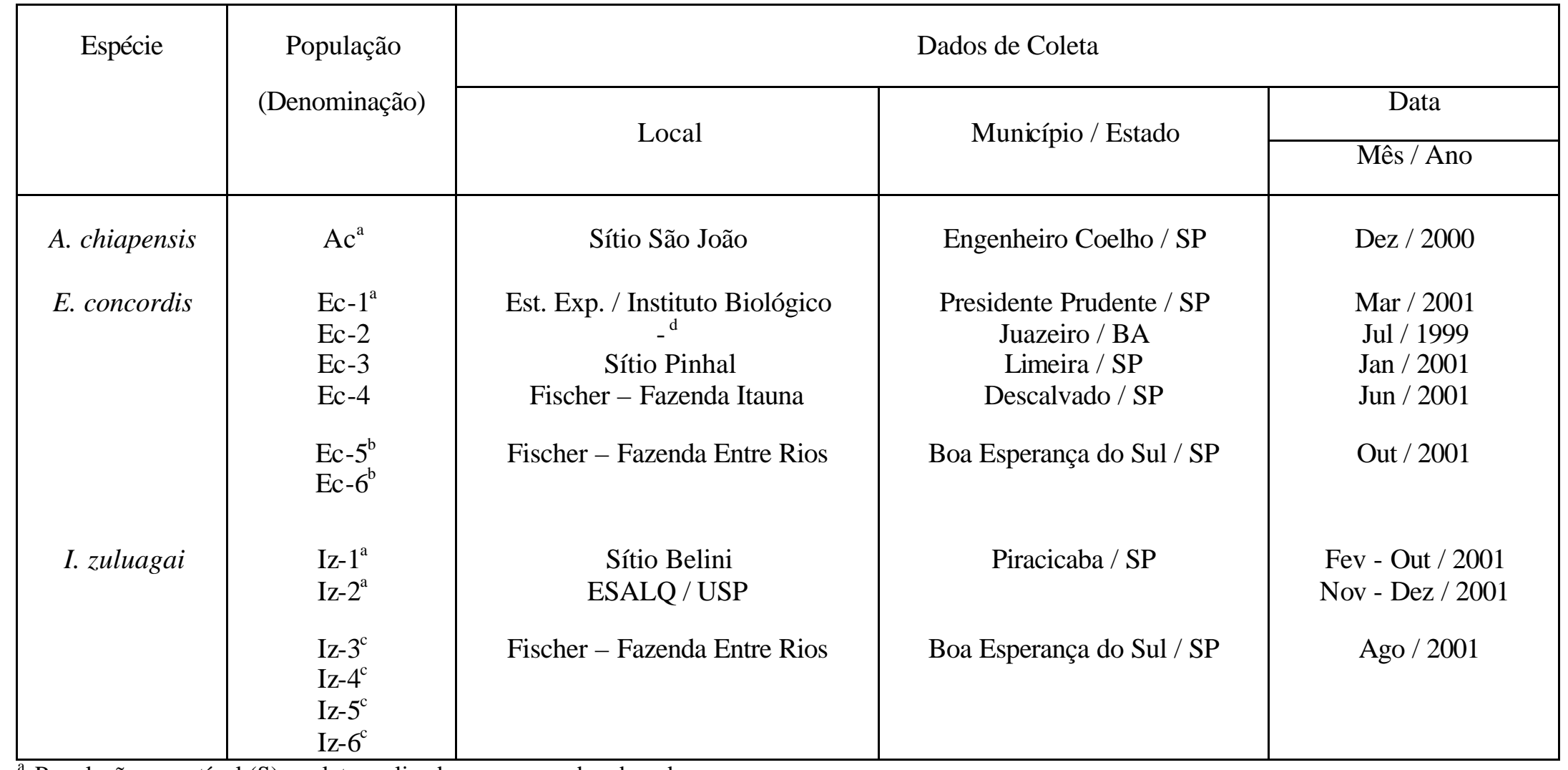

${ }^{a}$ População suscetível (S) : coleta realizada em pomar abandonado

${ }^{b, c}$ Populações provenientes de talhões distintos da propriedade

${ }^{\mathrm{d}}$ Local não especificado

Quadro 1 - Identificação das populações de Amblyseius chiapensis, Euseius concordis e Iphiseiodes zuluagai mantidas em criação em condições de laboratório, com seus respectivos dados de coleta. 


\begin{tabular}{|c|c|ccccc|}
\hline Espécie & \multirow{2}{*}{$\begin{array}{c}\text { População } \\
\text { (Denominação) }\end{array}$} & \multicolumn{5}{|c|}{ Ano / Número de Pulverizações } \\
\cline { 2 - 6 } & Ec-3 & $*$ & $*$ & - & 1 & 2 \\
& Ec-4 & 1 & - & 1 & 1 & - \\
& Ec-5 & - & - & - & - & 2 \\
& Ec-6 & - & - & 1 & 2 & 1 \\
& & & & & 1999 & \\
& Iz-3 & - & - & - & 1 & 1 \\
& Iz-4 & - & - & - & 1 & 2 \\
& Iz-5 & - & - & - & 1 & 2 \\
& Iz-6 & - & - & 1 & 1 & 1 \\
\hline
\end{tabular}

* Dados nã o fornecidos pelo proprietário da área

Quadro 2 - Número de pulverizações realizadas com inseticidas piretróides num período de cinco anos (1997 a 2001) em diferentes pomares comerciais onde foram realizadas coletas de populações de ácaros fitoseídeos.

A coleta das populações dos ácaros predadores foi realizada tomando-se folhas grandes e internas da copa de citros logo após a constatação da presença de fitoseídeos nas mesmas. Os ácaros foram transferidos para dentro de sacos de papel, que posteriormente foram acondicionados dentro de caixas térmicas contendo placas de gelo $\left(\operatorname{Gelox}^{\circledR}\right)$.

Esse material foi transportado para o laboratório, onde as fêmeas adultas coletadas em campo (aproximadamente de 100 a 500) foram transferidas com o auxílio de um microscópio estereoscópico e um pincel, para o interior de arenas de criação.

Após a colonização inicial das populações coletadas, amostras de ácaros foram retiradas para a identificação específica, utilizando-se a chave descrita por Lofego (1998). Posteriormente, a confirmação de A. chiapensis e E. concordis foi 
realizada pelo Prof. Dr. Gilberto José de Moraes (Departamento de Entomologia, Fitopatologia e Zoologia Agrícola - ESALQ/USP).

\subsection{Criação estoque em condições de laboratório}

\subsubsection{Amblyseius chiapensis e Euseius concordis}

Para a manutenção das populações de A. chiapensis e E. concordis em laboratório foram utilizadas arenas confeccionadas conforme metodologia modificada descrita por McMurtry \& Scriven (1965). Segundo Moraes (2000) esse método destacase como um dos mais efetivos para a criação de fitoseídeos, pois geralmente os ácaros dessa família são mantidos e multiplicados por técnicas que derivam dessa.

As arenas constituíram-se de caixas plásticas de diferentes tamanhos contendo em seu interior espuma embebida em água, sobre a qual foi colocada uma placa preta (Paviflex $^{\circledR}$ ) ou uma folha de feijão de porco Canavalia ensiformis (L.). Esse substrato foi devidamente circundado com algodão hidrófilo que foi mantido constantemente úmido. Foram colocados fios de algodão no centro da arena que permaneceram sob um pedaço de lamínula de vidro, com intuito de proporcionar aos ácaros um local para oviposição e abrigo. Como fonte de alimento, foi oferecida diariamente aos predadores uma pequena porção de pólen de taboa Typha angustifolia L. e eventualmente ovos e formas jovens de T. urticae. Com relação ao pólen, esse foi armazenado em refrigerador durante todo o período de criação dos ácaros fitoseídeos em laboratório.

Após a transferência dos ácaros, essas arenas foram mantidas sobre prateleiras em sala de criação com ambiente controlado à temperatura de $25 \pm 2{ }^{\circ} \mathrm{C}$, umidade relativa de $70 \pm 10 \%$ e fotofase de 14 horas, durante todo o período de realização dos bioensaios toxicológicos. 


\subsubsection{Iphiseiodes zuluagai}

Testes preliminares realizados para a criação de I. zuluagai mostraram que a técnica descrita anteriormente para A. chiapensis e E. concordis foi inadequada para a criação dessa espécie, pois o algodão umedecido foi ineficiente como barreira para impedir a fuga de I. zuluagai da arena de criação. Sendo assim, a técnica utilizada para a criação e manutenção de I. zuluagai em laboratório foi realizada seguindo a metodologia adaptada de Reis \& Alves (1997), utilizando-se água como barreira de contingência.

Cada unidade de criação constituiu-se de um disco plástico de coloração bege de 7,5 cm de diâmetro flutuando em água contida em uma placa de Petri de 9,2 cm de diâmetro. Um orifício no centro desse disco permitiu a passagem de um alfinete que foi fixado no centro da placa de Petri, o qual foi utilizado com o intuito de evitar que o disco tocasse a borda da placa, impedindo assim a fuga dos ácaros do interior da arena e assegurando o isolamento de cada população nessas condições.

Como descrito anteriormente para a criação de A. chiapensis e E. concordis, fios de algodão sob pedaços de lamínulas de vidro foram colocados no centro da arena, com o intuito de disponibilizar local para a oviposição e abrigo aos ácaros. Pólen de taboa foi oferecido diariamente como fonte de alimento.

As arenas foram mantidas individualizadas no interior de caixas plásticas brancas de 41,0 x 34,0 x 14,0 cm, sendo que as mesmas foram sombreadas pela utilização de um anteparo preto de 35,0 x 30,0 cm, proporcionando dessa maneira um ambiente de penumbra, favorável ao desenvolvimento desses ácaros.

Durante o período de realização dos bioensaios toxicológicos foram mantidas aproximadamente quatro caixas contendo em média nove arenas cada. Essas caixas foram mantidas em bancadas, em sala de criação com ambiente controlado à temperatura de $25 \pm 2{ }^{\circ} \mathrm{C}$, umidade relativa de $70 \pm 10 \%$ e fotofase de 14 horas, ond e permaneceram durante todo o período de realização dos bioensaios. 


\subsection{Avaliação das variabilidades inter e intraespecífica ao acaricida dicofol}

Avaliou-se a variabilidade interespecífica de resposta ao acaricida dicofol para A. chiapensis, E. concordis e I. zuluagai, utilizando as populações denominadas: Ac, Ec-1 e Iz-1 oriundas de pomares abandonados (Quadro 1). Quanto à variabilidade intraespecífica, essa foi analisada utilizando-se três populações de E. concordis sendo: Ec-1, Ec-2 e Ec-3, tomando a primeira como suscetível de referência (S).

\subsubsection{Bioensaios toxicológicos}

O bioensaio empregado para avaliar as respostas dos ácaros fitoseídeos ao acaricida dicofol (Kelthane $480 \mathrm{CE}^{\circledR}$, Rohm and Haas Química Ltda.) foi o de contato residual, realizando-se a pulverização da suspensão do produto sobre superfície de vidro com o uso da torre de Potter (Burkard Manufacturing, Rickmansworth, Inglaterra) calibrada à pressão de $10 \mathrm{psi}(68,95 \mathrm{kPa})$. Foi utilizado um volume de $2,0 \mathrm{ml}$ de suspensão, com deposição média obtida para o resíduo úmido de aproximadamente $1,56 \mathrm{mg} / \mathrm{cm}^{2}$.

Logo após a pulverização, as superfícies contendo o resíduo úmido foram deixadas para secar em condições de laboratório, por um período de aproximadamente 40 minutos antes do preparo das arena para bioensaio.

\subsubsection{Amblyseius chiapensis e Euseius concordis}

A superfície de aplicação para os bioensaios com A. chiapensis e E. concordis foram lâminas de vidro de 5,0 x 5,0 cm. Após a secagem do resíduo cada lâmina foi depositada sobre uma placa preta $(5,0 \times 5,0 \mathrm{~cm})\left(\right.$ Paviflex $\left.^{\circledR}\right)$ colocada sobre uma espuma (7,0 x 7,0 cm) embebida em água. A placa preta foi utilizada para facilitar a visualização dos ácaros por ocasião da avaliação do bioensaio. As bordas da lâmina foram circundadas com uma fina camada de algodão hidrófilo umedecido com o intuito de conter a fuga dos predadores do interior da arena e ao mesmo tempo fornecer água aos 
mesmos. Posteriormente, com uso de um pincel e um microscópio estereoscópio, dez fêmeas adultas, com idade que variou de 7 a 15 dias, foram transferidas no interior de cada arena. Essas arenas foram mantidas dentro de caixas plásticas de 24,0 x 17,0 x 5,0 $\mathrm{cm}$ abertas, as quais permaneceram em câmaras climatizadas à temperatura de $25 \pm 2^{\circ} \mathrm{C}$, umidade relativa de $70 \pm 10 \%$ e fotofase de 14 horas. Como fonte de alimento, uma pequena porção de pólen de taboa foi fornecida aos predadores no centro da arena (Figura 2A).

\subsubsection{Iphiseiodes zuluagai}

Para I. zuluagai, foram utilizadas arenas de bioensaio confeccionadas conforme metodologia adaptada de Reis (1996). Dessa forma, utilizou-se lamínulas de vidro de 2,0 x 2,0 cm como superfície de aplicação que, após a pulverização da suspensão e secagem do resíduo úmido em condições de laboratório, foram colocadas para flutuar em uma lâmina de água contida em placa de Petri $3,5 \mathrm{~cm}$ (Falcon 1008, Becton Dickinson Labware, Lincoln Park, NJ, Estados Unidos).

Da mesma forma que o bioensaio descrito anteriormente para as demais espécies, dez fêmeas adultas, com idade que variou de 7 a 15 dias, foram transferidas com uso de um pincel e um microscópio estereoscópio, para cada arena, as quais foram posteriormente mantidas dentro de caixas plásticas abertas, permanecendo posteriormente em câmaras climatizadas à temperatura de $25 \pm 2^{\circ} \mathrm{C}$, umidade relativa de $70 \pm 10 \%$ e fotofase de 14 horas. Também para essa espécie, pólen de taboa foi fornecido como fonte de alimento. A água mostrourse mais eficiente que o algodão hidrófilo umedecido como barreira de contingência, optando-se dessa forma por esse tipo de arena para bioensaio (Figura 2B).

\subsubsection{Caracterização da linha básica de suscetibilidade}

Para a caracterização da linha básica de suscetibilidade ao dicofol para as três espécies de fitoseídeos, foram utilizadas de cinco a sete concentrações distribuídas 
logaritmicamente entre 10 e $320 \mathrm{mg}$ de dicofol/L água destilada [I.A. (ppm)], utilizando-se de cinco a oito repetições para cada concentração testada.

A avaliação do bioensaio foi realizada 24 horas após a infestação dos ácaros, sendo observado o número de ácaros mortos em cada arena. Deve-se observar que foram considerados mortos, os indivíduos que não responderam com movimentos vigorosos e imediatos ao serem tocados com o auxílio de um pincel. Quanto aos dados de mortalidade para cada espécie e população em questão, os mesmos foram submetidos à análise de Probit utilizando-se o programa POLO-PC (LeOra Software, 1987) para a estimativa da $\mathrm{CL}_{50}$ e teste de paralelismo e igualdade com intuito de comparar as linhas de concentração-mortalidade estabelecidas para cada espécie e população em estudo.

\subsection{Avaliação da variabilidade interespecífica de Euseius concordis e Iphiseiodes zuluagai à deltametrina}

\subsubsection{Bioensaios toxicológicos}

Realizou-se a caracterização da suscetibilidade de E. concordis e I. zuluagai à deltametrina (Decis $25 \mathrm{CE}^{\circledR}$, Aventis CropScience Brasil Ltda.), avaliando-se as respostas de concentração-mortalidade das populações Ec-1 e Iz-1 com bioensaio de contato direto.

Sobre uma lamínula de 2,0 x 2,0 cm flutuando em água contida no interior de uma placa de Petri de 3,5 cm de diâmetro, foram transferidas 20 fêmeas adultas com idade que variou de 7 a 15 dias, as quais receberam pulverização direta da suspensão do inseticida realizada com o auxílio da torre de Potter. Discos de folha de citros de 2,6 cm de diâmetro também foram pulverizados na parte adaxial.

A aplicação de 2,0 ml de suspensão de deltametrina, da mesma forma que o observado anteriormente para os bioensaios com dicofol, também resultou em uma deposição média de aproximadamente $1,56 \mathrm{mg}$ de resíduo úmido/ $\mathrm{cm}^{2}$ de área pulverizada. 
Tanto as arenas com os ácaros quanto os discos de folha permaneceram em condições de laboratório para a secagem do inseticida pulverizado. Após a secagem, os discos de folha foram acondicionados individualmente sobre uma mistura ainda não geleificada de ágar-água a 3\%, contida no interior de uma placa de Petri de 3,5 cm de diâmetro. Após a geleificação do substrato no fundo da placa, uma borda no disco de folha foi feita utilizando-se a mistura ágar-água com a finalidade de manter túrgido o mesmo durante o período do bioensaio.

Em seguida, foi transferido para o centro do disco, uma pequena quantidade de pólen de taboa, fornecido como fonte de alimento aos ácaros. Posteriormente, realizour se a transferência de cinco fêmeas para cada arena (Figura 2C), sendo que as mesmas

foram fechadas posteriormente com filme plástico transparente (Magipack ${ }^{\circledR}$ ), evitandose portanto a fuga dos ácaros do interior da mesma.

Essas arenas foram mantidas dentro de caixas plásticas de 24,0 x 17,0 x 5,0 cm, as quais permaneceram em câmaras climatizadas à temperatura de $25 \pm 2^{\circ} \mathrm{C}$ e fotofase de 14 horas.

\subsubsection{Caracterização da linha básica de suscetibilidade}

Foram utilizadas de cinco a sete concentrações para a caracterização toxicológica e obtenção das curvas de concentração-mortalidade, as quais foram distribuídas logaritmicamente e variaram de 10 e 100 mg de deltametrina/L água destilada [I.A.(ppm)] para E. concordis, e de 0,32 a $10 \mathrm{mg}$ de deltametrina/L água destilada [I.A.(ppm)] para I. zuluagai, realizando-se de cinco a oito repetições para cada concentração testada.

A avaliação do bioensaio foi realizada 48 horas após a infestação dos ácaros, sendo observado o número de ácaros mortos por arena. Os dados de mortalidade para cada espécie foram submetidos à análise de Probit utilizando-se o programa POLO-PC (LeOra Software, 1987) para a estimativa da $\mathrm{CL}_{50}$ e teste de paralelismo e igualdade para comparar os coeficientes angular e linear obtidos para as retas de regressão estabelecidas para cada espécie. 
Foram considerados mortos os indivíduos que não responderam com movimentos vigorosos e imediatos ao serem tocados com a ponta de um estilete utilizado por ocasião da avaliação. A razão de tolerância (RT) foi estimada através da divisão da $\mathrm{CL}_{50}$ da espécie mais tolerante pela $\mathrm{CL}_{50}$ da espécie menos tolerante à deltametrina.

\subsection{Monitoramento da suscetibilidade de populações de Euseius concordis e Iphiseiodes zuluagai à deltametrina}

Empregando-se a concentração de $10 \mathrm{mg}$ de deltametrina/L de água destilada [I.A.(ppm)] foi avaliada a suscetibilidade de seis populações de E. concordis (Ec-1, Ec-2, Ec-3, Ec-4, Ec-5 e Ec-6) e seis populações de I. zuluagai (Iz-1, Iz-2, Iz-3, Iz-4, Iz-5 e Iz-6), com o intuito de verificar as variabilidades inter e intraespecífica de respostas das mesmas a esse produto. Essa concentração foi tomada como diagnóstica devido aos resultados obtidos nos bioensaios de variabilidade interespecífica realizados anteriormente, e por aproximar-se da concentração recomendada para o controle de insetos pragas na cultura de citros $(12,5 \mathrm{mg}$ de deltametrina/L de água). O método de bioensaio utilizado foi o mesmo descrito no item anterior.

A avaliação do bioensaio foi realizada 48 horas após a pulverização, observando-se o número de ácaros mortos por arena. Consideroutse como mortos os indivíduos que não responderam com movimentos vigorosos e imediatos ao serem tocados com a ponta de um pincel, utilizado por ocasião da avaliação.

Os dados de porcentagem de mortalidade corrigida $(X)$ foram transformados em

$\operatorname{arc} \operatorname{sen} \sqrt{(X / 100)}$ e submetidos à análise de variância hierárquica para avaliar os efeitos da espécie e de populações dentro de cada espécie. As médias dos tratamentos foram comparadas através do teste de Tukey ao nível de significância de $\alpha=0,05$. 


\subsection{Avaliação da variabilidade intraespecífica de populações de Euseius concordis e Iphiseiodes zuluagai à deltametrina}

Com o intuito de verificar a ocorrência da variabilidade intraespecífica entre diferentes populações de E. concordis e I. zuluagai, foram avaliadas as respostas de concentração-mortalidade das populações Ec-1, Ec-2 e Ec-3 e Iz-1, Iz-3, Iz-4 e Iz-6. O método de bioensaio foi o mesmo descrito no item 3.4.1.

\subsubsection{Caracterização toxicológica}

Para a caracterização toxicológica e obtenção das curvas de regressão concentração-mortalidade, foram utilizadas de cinco a sete concentrações distribuídas logaritmicamente e variando de 10 e $3200 \mathrm{mg}$ de deltametrina/L de água destilada [I.A. (ppm)] para as populações de $E$. concordis e de 0,32 a $56 \mathrm{mg}$ de deltametrina/L de água destilada [I.A. (ppm)] para as populações de I. zuluagai. Da mesma forma que nos bioensaios para a avaliação da variabilidade interespecífica, foram realizadas de cinco a oito repetições para cada concentração testada.

A avaliação do bioensaio foi realizada 48 horas após a pulverização, observando-se o número de ácaros mortos por arena. Os dados de mortalidade para cada população foram submetidos à análise de Probit utilizando-se o programa POLO-PC (LeOra Software, 1987) para a estimativa da $\mathrm{CL}_{50}$ e teste de paralelismo e igualdade, com intuito de determinar se os coeficientes angular e linear estabelecidos para cada linha de concentração-mortalidade diferiram significativamente dos estimados para a população S. A razão de resistência (RR) foi estimada por meio da divisão da $\mathrm{CL}_{50}$ da população em estudo pela $\mathrm{CL}_{50}$ da população tomada como suscetível de referência (S). 


\subsection{Avaliação da variabilidade nas respostas de repelência à deltametrina nas populações Ec-1 e Ec-3 de Euseius concordis}

O bioensaio de contato residual foi utilizado para verificar o efeito de repelência de deltametrina sobre as populações Ec-1 e Ec-3 de E. concordis à deltametrina.

Discos de folha de citros de 2,6 cm de diâmetro foram pulverizados em sua parte adaxial com o uso da torre de Potter. Após a pulverização, os discos foram mantidos por um período de aproximadamente 40 minutos em condições laboratoriais para a secagem do resíduo úmido. Posteriormente, os discos foram colocados para flutuar sobre uma lâmina de água contida no interior de uma placa de Petri de 5,6 cm de diâmetro. Um orifício foi previamente realizado no centro dos discos de folha, o qual permitiu a passagem de um alfinete fixo no centro da placa de Petri, sendo que tal procedimento foi adotado para que os discos não tocassem a borda da placa durante o bioensaio (Figura 2D).

Foram utilizadas de cinco a sete concentrações distribuídas logaritmicamente entre 10 e $3200 \mathrm{mg}$ de deltametrina/L de água destilada [I.A.(ppm)], testando-se 50 ácaros (fêmeas adultas) por concentração.

A avaliação do bioensaio foi realizada 24 horas após a infestação dos ácaros, sendo observado o número de ácaros presentes na arena e o número de indivíduos na água devido a repelência causada pelo produto. Os dados de repelência para cada população foram submetidos à análise de Probit utilizando-se o programa POLO-PC (LeOra Software, 1987) para a estimativa da CRep $_{50}$ (concentração que causou a repelência de 50\% dos indivíduos testados).

A razão de repelência (RRep) para as populações testadas inicialmente seria obtida pela divisão da $\mathrm{CRep}_{50}$ estimada para a população que apresentourse menos afetada pelo resíduo do produto, pela $\operatorname{CRep}_{50}$ estimada para a população que apresentou maior dispersão devido ao efeito de repelência causado pelo produto. Porém, devido às respostas exibidas pela população Ec-3, a RRep foi obtida pela divisão da concentração mais alta testada para a população Ec-3 pela CRep 50 estimada para a população Ec-1. 

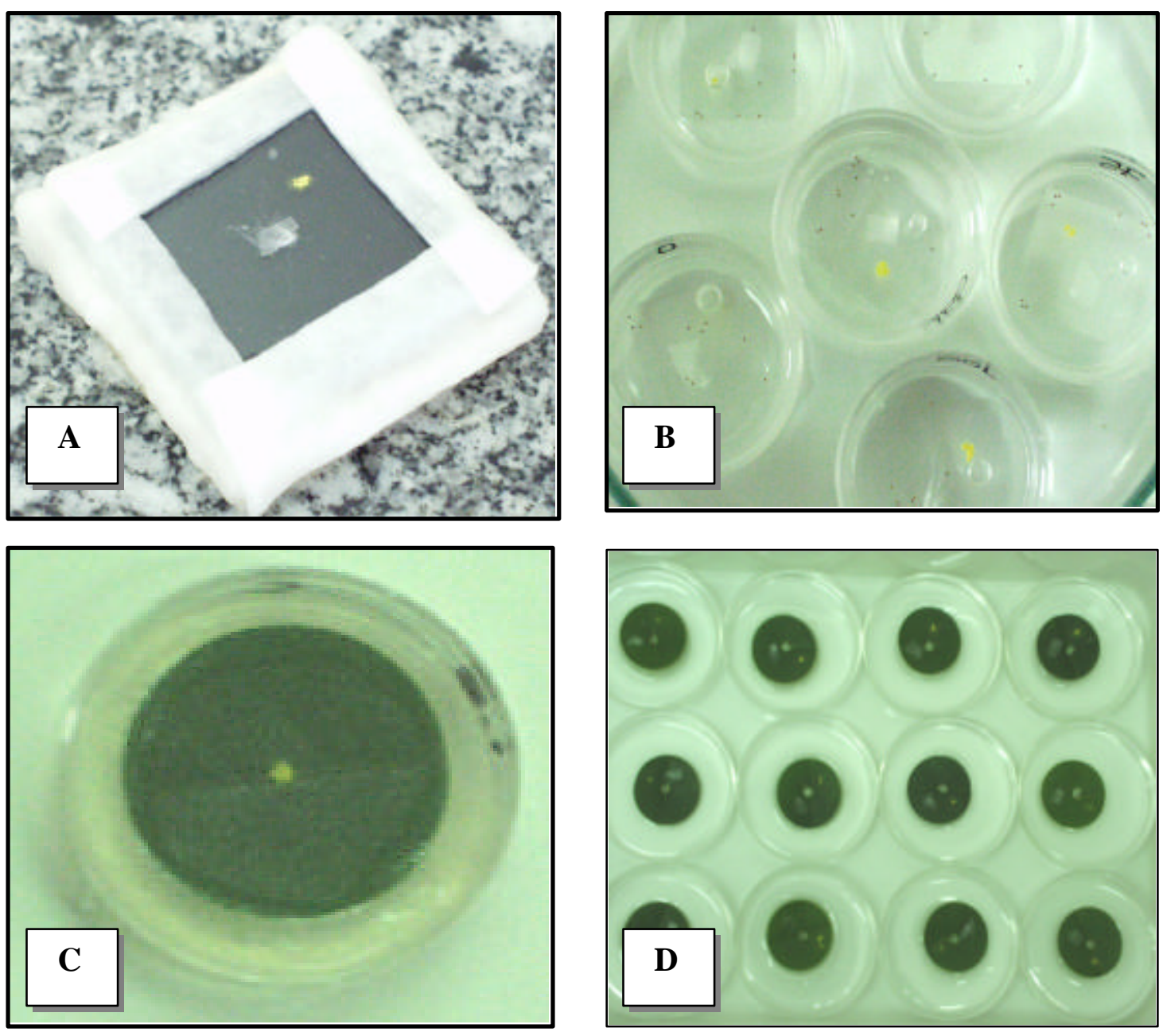

Figura 2 - (A, B) Arenas utilizadas nos bioensaios realizados para a avaliação da suscetibilidade de Amblyseius chiapensis, Euseius concordis e Iphiseiodes zuluagai ao dicofol. (C) Arena utilizada nos bioensaios realizados para a avaliação da suscetibilidade de Euseius concordis e Iphiseoides zuluagai à deltametrina. (D) Arena utilizada nos bioensaios realizados para avaliar a variabilidade nas respostas de repelência à deltametrina nas populações $\mathrm{Ec}-1$ e Ec-3 de Euseius concordis. 


\section{RESULTADOS E DISCUSSÃO}

\subsection{Avaliação das variabilidades inter e intraespecífica ao acaricida dicofol}

As respostas de concentração-mortalidade de Amblyseius chiapensis DeLeon, E. concordis (Chant) e Iphiseiodes zuluagai Denmark \& Muma ao acaricida dicofol estão representadas na Tabela 1. Para a caracterização toxicológica dessas espécies foram utilizadas 232, 314 e 197 fêmeas respectivamente.

Para A. chiapensis (Ac), a $\mathrm{CL}_{50}$ estimada foi de $85,10 \mathrm{mg}$ de dicofol/L de água destilada [I.A.(ppm)] (I.C. 95\% 72,56-97,52), coeficiente angular ( \pm desvio padrão) de $3,31 \pm 0,46$ e qui-quadrado $\left(\chi^{2}\right)$ de 1,76 (graus de liberdade (g.l.) $=3 ; P>0,05$ ). Para E. concordis (Ec-1) foi obtida uma $\mathrm{CL}_{50}$ de $109,28 \mathrm{mg}$ de dicofol/L de água destilada [I.A.(ppm)] (I.C. 95\% 71,56-144,40), coeficiente angular ( \pm desvio padrão) de $3,38 \pm 0,52$ e qui-quadrado $\left(\chi^{2}\right)$ de 5,23 (graus de liberdade (g.l.) $=3 ; P>0,05$ ). E para para I. zuluagai (Iz-1), a $\mathrm{CL}_{50}$ foi de $95,37 \mathrm{mg}$ de dicofol/L de água destilada [I.A.(ppm)] (I.C. 95\% 81,33-110,05), coeficiente angular ( \pm desvio padrão) de $3,38 \pm 0,55$ e qui-quadrado $\left(\chi^{2}\right)$ de 1,81 (graus de liberdade (g.l.) $=4 ; P>0,05$ ).

Como foi verificada a sobreposição dos intervalos de confiança das $\mathrm{CL}_{50} \mathrm{~s}$ estimadas para cada espécie, pode-se concluir que não há diferenças significativas quanto à suscetibilidade dessas espécies ao acaricida dicofol, não ocorrendo portanto, variabilidade interespecífica de resposta a esse produto. Através dos testes de paralelismo e de igualdade, foram verificadas que as linhas de concentração-resposta obtidas para essas três espécies, apresentaram praticamente o mesmo coeficiente angular, sendo consideradas portanto paralelas e sobrepostas. 
Tabela 1. Respostas de concentração-mortalidade de Amblyseius chiapensis, Euseius concordis e Iphiseiodes zuluagai ao dicofol.

\begin{tabular}{|c|c|c|c|c|c|}
\hline $\begin{array}{c}\text { Espécie } \\
\text { (População) }\end{array}$ & $\mathrm{n}^{\mathrm{a}}$ & $\begin{array}{c}\mathrm{CL}_{50}(\mathrm{mg} \text { I. A./L) } \\
(95 \% \text { IC) }\end{array}$ & $\begin{array}{c}\text { Coeficiente } \\
\text { Angular } \pm \text { EP }\end{array}$ & $\chi^{2}$ & g.1. \\
\hline $\begin{array}{l}\text { A. chiapensis } \\
\text { (Ac) }\end{array}$ & 232 & $\begin{array}{c}85,10 \\
(72,56-97,52)\end{array}$ & $3,31 \pm 0,46$ & 1,76 & 3 \\
\hline $\begin{array}{c}\text { E. concordis } \\
(\mathrm{Ec}-1)\end{array}$ & 314 & $\begin{array}{c}109,28 \\
(71,56-144,40)\end{array}$ & $3,38 \pm 0,52$ & 5,23 & 3 \\
\hline $\begin{array}{l}\text { I. zuluagai } \\
\text { (Iz-1) }\end{array}$ & 197 & $\begin{array}{c}95,37 \\
(81,33-110,05)\end{array}$ & $3,38 \pm 0,55$ & 1,81 & 4 \\
\hline
\end{tabular}

${ }^{a}$ Número de ácaros testados

Observando-se que a concentração recomendada para o controle de Brevipalpus phoenicis (Geijskes) em campo é de aproximadamente $320 \mathrm{mg}$ de dicofol/L de água destilada [I.A.(ppm)], e que as $\mathrm{CL}_{50} \mathrm{~s}$ estimadas para todas as espécies nesse estudo permaneceram abaixo dessa, possivelmente o acaricida dicofol apresente um elevado efeito negativo sobre esses predadores no campo.

Esses resultados confirmaram o efeito nocivo do dicofol reportados por Komatsu \& Nakano (1988) e Reis et al. (1998b) sobre E. concordis e I. zuluagai respectivamente. Childers et al. (2001) também evidenciaram o efeito negativo desse acaricida sobre Euseius mesembrinus (Dean) (considerado um importante inimigo natural de ácaros-pragas nos pomares de citros da Flórida/EUA) verificando que o resíduo de quatro dias após a aplicação em campo foi altamente tóxico às fêmeas dessa espécie.

Ressalta-se que na presente pesquisa, o único critério adotado para avaliação foi o de mortalidade, porém, sabe-se que esse produto pode afetar significativamente a 
fecundidade dos ácaros fitoseídeos. Por exemplo, Reis et al. (1998b) evidenciaram que esse produto afetou significativamente a reprodução de I. zuluagai em condições de laboratório. Do mesmo modo, Suárez et al. (1997) verificaram que a partir de $10 \mathrm{mg}$ de dicofol/L de água destilada [I.A.(ppm)] ocorreu uma significativa redução na oviposição de E. mesembrinus (considerado também, um importante predador de ácaros tetraniquídeos e Brevipalpus californicus (Banks) em pomares de citros no México). Esse acaricida também afetou significativamente a oviposição de fêmeas de Euseius stipulatus Athias-Henriot, por um período que se estendeu até 76 dias após o tratamento (Morse et al., 1987). Dessa forma, pode-se inferir que além do efeito direto do dicofol sobre os ácaros fitoseídeos, indiretamente o mesmo também pode inteferir de forma negativa sobre esses organismos.

Portanto, a interferência negativa da utilização do dicofol pode ser observada sobre várias espécies de ácaros fitoseídeos, mesmo aquelas que ocorrem em baixas densidades populacionais, como é o caso de A. chiapensis (Sato et al., 1994), o que poderia ocasionar um desequilíbrio ecológico no pomar de citros, afetando diretamente o controle biológico e indiretamente o manejo do ácaro-da-leprose, o que poderá ocasionar surtos progressivos dessa praga.

Quanto à variabilidade intraespecífica, as respostas de concentraçãomortalidade obtidas para as populações Ec-1, Ec-2 e Ec-3 de E. concordis, encontram-se resumidas na Tabela 2. Para a caracterização toxicológica foram utilizadas 314, 586 e 418 fêmeas adultas respectivamente.

Com relação à população Ec-1, a $\mathrm{CL}_{50}$ estimada foi de 109,28 mg de dicofol/L de água destilada [I.A.(ppm)] (I.C. 95\% 71,56-144,40), coeficiente angular $( \pm$ desvio padrão) de 3,38 $\pm 0,52$ e qui-quadrado $\chi^{2}$ ) de 5,23 (graus de liberdade (g.l.) = 3; $P>0,05)$. Para a população Ec-2, a $\mathrm{CL}_{50}$ estimada foi de $97,91 \mathrm{mg}$ de dicofol/L de água destilada [I.A. (ppm)] (I.C. 95\% 89,17-107,26), coeficiente angular ( \pm desvio padrão) de 4,75 $\pm 0,46$ e qui-quadrado $\left(\chi^{2}\right)$ de 4,53 (graus de liberdade (g.l.) $=4 ; P>0,05$ ). Com relação à população Ec-3, a $\mathrm{CL}_{50}$ foi de $85,67 \mathrm{mg}$ de dicofol/L de água destilada 
[I.A.(ppm)] (I.C. 95\% 76,35-94,95), coeficiente angular ( \pm desvio padrão) de 4,13 \pm 0,47 e qui-quadrado $\left(\chi^{2}\right)$ de 2,00 (graus de liberdade (g.l.) $=3 ; P>0,05$ ).

Tabela 2. Respostas de concentração-mortalidade das populações Ec-1, Ec-2 e Ec-3 de Euseius concordis ao dicofol.

\begin{tabular}{cccccc}
\hline População & $\mathrm{n}^{\text {a }}$ & $\begin{array}{c}\text { CL } 50 \text { (mg I. A./L) } \\
(95 \% \text { IC })\end{array}$ & $\begin{array}{c}\text { Coeficiente } \\
\text { Angular } \pm \text { EP }\end{array}$ & $\chi^{2}$ & g.l. \\
\hline Ec-1 & 314 & $\begin{array}{c}109,28 \\
(71,56-144,40)\end{array}$ & $3,38 \pm 0,52$ & 5,23 & 3 \\
& & & & \\
Ec-2 & 586 & $\begin{array}{c}97,91 \\
(89,17-107,26)\end{array}$ & $4,75 \pm 0,46$ & 4,53 & 4 \\
& & & & & \\
Ec-3 & 418 & 85,67 & $4,13 \pm 0,47$ & 2,00 & 3 \\
& & $(76,35-94,95)$ & & & \\
\hline
\end{tabular}

${ }^{\mathrm{a}}$ Número de ácaros testados

Devido à sobreposição dos intervalos de confiança das $\mathrm{CL}_{50} \mathrm{~s}$ estimadas para as três populações de E. concordis, não foi detectada variabilidade intraespecífica ao acaricida dicofol, fato que foi confirmado nos testes de paralelismo e igualdade, através do qual, observoutse a sobreposição das linhas de concentração-mortalidade para essas populações.

Observando-se que em alguns pomares paulistas, a ocorrência de populações de B. phoenicis com alta freqüência de indivíduos resistentes ao acaricida dicofol já foi detectada (Omoto et al., 2000), provavelmente possam existir áreas, onde através de um processo de utilização contínua desse produto, a freqüência de ácaros fitoseídeos resistentes também apresente-se em nível relativamente alto. Neste estudo porém, avalioutse as respostas de poucas populações de E. concordis, sendo que a população 
Ec-2 da mesma forma que a Ec-1 (tomada nesse caso como suscetível de referência) foi coletada em pomar abandonado onde o dicofol não tem sido utilizado a um tempo considerável, fato esse que possivelmente foi responsável pela alta suscetibilidade apresentada por essa população. Com relação à população Ec-3, proveniente de um pomar comercial no município de Limeira/SP, também demonstrou elevada suscetibilidade a esse produto.

\subsection{Avaliação da variabilidade interespecífica de Euseius concordis e Iphiseiodes zuluagai à deltametrina}

As respostas de concentração-mortalidade de E. concordis (Ec-1) e I. zuluagai (Iz-1) à deltametrina estão expressas na Tabela 3. Foram testadas 505 e 289 fêmeas adultas respectivamente. Para E. concordis a CL50 estimada foi de 35,35 mg de deltametrina/L de água destilada [I.A.(ppm)] (I.C. 95\% 19,87-53,30), coeficiente angular ( \pm desvio padrão) de 2,60 $\pm 0,29$ e qui-quadrado $\left(\chi^{2}\right)$ de 7,85 (graus de liberdade (g.l.) $=3 ; P>0,05)$. Com relação a $I$. zuluagai, a $\mathrm{CL}_{50}$ estimada foi de $0,71 \mathrm{mg}$ de deltametrina/L de água destilada [I. A. (ppm)] (I.C. 95\% 0,32-1,14), coeficiente angular $\left( \pm\right.$ desvio padrão) de 1,50 \pm 0,24 e qui-quadrado $\left(\chi^{2}\right)$ de 5,65 (graus de liberdade $(\mathrm{g} .1)=$. $5 ; P>0,05)$. Não houve sobreposição dos intervalos de confiança das $\mathrm{CL}_{50} \mathrm{~s}$ estimadas para ambas espécies, verificando-se, portanto, a presença de variabilidade interespecífica de resposta à deltametrina, o que foi comprovado nos testes de paralelismo e igualdade, através do qual, pôde-se verificar que não ocorreu a sobreposição das linhas de concentração-mortalidade, sendo as mesmas consideradas distintas e não paralelas (Figura 3).

A proporção na diferença de suscetibilidade apresentada por essas espécies foi estimada através da razão de tolerância (RT), evidenciando que E. concordis apresentouse aproximadamente 50 vezes mais tolerante a esse produto do que I. zuluagai (Tabela 3). Markwick (1986) realizando bionsaios para avaliar a variabilidade nas respostas de Typhlodromus pyri Scheuten e Phytoseiulus persimilis Athias-Henriot à cipermetrina, deltametrina e fenvalerate, também detectou uma suscetibilidade 
diferencial, inferindo que todos esses piretróides foram mais tóxicos a $P$. persimilis do que para a outra espécie em estudo, sendo que com relação à deltametrina, o mesmo mostrou-se 314 vezes mais suscetível do que T. pyri.

Tabela 3. Respostas de concentração-mortalidade de Euseius concordis e Iphiseiodes zuluagai à deltametrina.

\begin{tabular}{ccccccc}
\hline $\begin{array}{c}\text { Espécie } \\
\text { (População) }\end{array}$ & $\mathrm{n}^{\text {a }}$ & $\begin{array}{c}\text { CL } 50 \text { (mg I. A./L) } \\
(95 \% \text { IC) }\end{array}$ & $\begin{array}{c}\text { Coeficiente } \\
\text { Angular } \pm \text { EP }\end{array}$ & $\chi^{2}$ & g.l. & RT $^{\text {b }}$ \\
\hline $\begin{array}{c}\text { E. concordis } \\
\text { (Ec-1) }\end{array}$ & 505 & $\begin{array}{c}35,35 \\
(19,87-53,30)\end{array}$ & $2,60 \pm 0,29$ & 7,85 & 3 & 49,79 \\
$\begin{array}{c}\text { I. zuluagai } \\
\text { (Iz-1) }\end{array}$ & 289 & $\begin{array}{c}0,71 \\
(0,32-1,14)\end{array}$ & $1,50 \pm 0,24$ & 5,65 & 5 & - \\
\hline
\end{tabular}

${ }^{a}$ Número de ácaros testados

${ }^{\mathrm{b}} \mathrm{RT}=$ Razão de Tolerância: $\mathrm{CL}_{50}$ E. concordis / $\mathrm{CL}_{50}$ I. zuluagai

Verificando que os parâmetros biológicos de E. concordis e I. zuluagai apresentam-se semelhantes segundo os dados reportados na literatura (Komatsu \& Nakano, 1988; Moraes \& Lima, 1983; Reis et al., 1998a), provavelmente o fato de E. concordis ter apresentado uma tolerância maior à deltametrina do que I. zuluagai possa estar relacionado a outros fatores.

Deve-se observar que mesmo apesar de ambas espécies terem sido submetidas à aplicação direta de deltametrina nos bioensaios realizados, o período de exposição ao resíduo do produto para cada uma pode ter sido diferente, uma vez que a arena utilizada além de apresentar uma área contendo resíduo de deltametrina (disco de folha de citros) também apresentava uma área não-tratada. Assim dentro de um contexto ecológico, supondo-se que E. concordis apresente uma maior mobilidade associada a uma elevada repelência quando em contato com o resíduo de deltametrina, o mesmo provavelmente tenha permanecido menos exposto sobre o resíduo do que I. zuluagai. 
Ressalta-se que a absorção de deltametrina ocorre principalmente através do contato tarsal, sendo que quanto maior o tempo de exposição do ácaro predador sobre o resíduo do produto, maior o efeito do mesmo sobre esse organismo. Em condições de campo, após a aplicação de deltametrina, possivelmente E. concordis possa emigrar para áreas não tratadas, o que provavelmente ocorrerá em uma menor intensidade com I. zuluagai. Nesse sentido, sugere-se que estudos futuros sejam realizados com intuito de verificar a ocorrência de variabilidade interespecífa quanto ao efeito de repelência de deltametrina sobre E. concordis e I. zuluagai, para que dessa forma possa-se confirmar a hipótese levantada neste trabalho.

Deve-se ainda enfatizar que a maior tolerância exibida por E. concordis à deltametrina, pode estar ligada a fatores fisiológicos intrínsecos a essa espécie, fazendo com que E. concordis através de um processo bioquímico, apresente uma maior capacidade de degradação da molécula de deltametrina do que I. zuluagai.

A estimativa da linha básica de suscetibilidade à deltametrina realizada para cada espécie em questão, contribuirá para o monitoramento da resistência a esse produto em uma determinada população em estudo, uma vez que a partir dessa, poderão ser distinguidas respostas devido à tolerância inata ou à uma variabilidade intrínseca em populações de uma mesma espécie a esse produto.

Dentro de um contexto prático, verificando que a concentração de campo de deltametrina recomendada para o controle de insetos-pragas (por exemplo cigarrinhas, bicho-furão e mosca-das-frutas) em pomares comerciais de citros é de aproximadamente 12,5 mg de deltametrina/L de água destilada [I.A.(ppm)], pode-se levantar a hipótese que a utilização desse produto, pode afetar principalmente as populações de I. zuluagai, e que de modo contrário, E. concordis será capaz de tolerar às aplicações de deltametrina realizadas em campo.

Em alguns trabalhos de levantamento de ácaros fitoseídeos realizados em pomares onde não foram efetuadas pulverizações com defensivos químicos, I. zuluagai tem sido considerada a espécie predominante (Moreira, 1993; Reis et al., 2000a; Sato et al., 1994). Desse modo, sabendo-se que o regime de pulverização com inseticidas piretróides pode afetar drásticamente a ocorrência dessa espécie em pomares comerciais, 
e provavelmente a realização de levantamentos populacionais de ácaros predadores nessas áreas possam indicar uma alteração na dinâmica populacional da mesma.

Portanto, a interferência negativa do controle químico sobre I. zuluagai, que é uma espécie comprovadamente efetiva na predação de Brevipalpus phoenicis (Geijskes) (Reis et al., 2000b), pode afetar diretamente o manejo desse ácaro praga, acarretando aumento nos custos de produção, bem como, freqüentes falhas no controle devido ao aumento da freqüência dos indivíduos resistentes (Omoto, 1995). Desse modo, é aconselhável a utilização de produtos que apresentem um espectro de ação restrito ao alvo, para preservar o equilíbrio ecológico entre os ácaros fitófagos e seus inimigos naturais, e minimizar os prejuízos atualmente vigentes na citricultura devido à intensa utilização de pesticidas. 


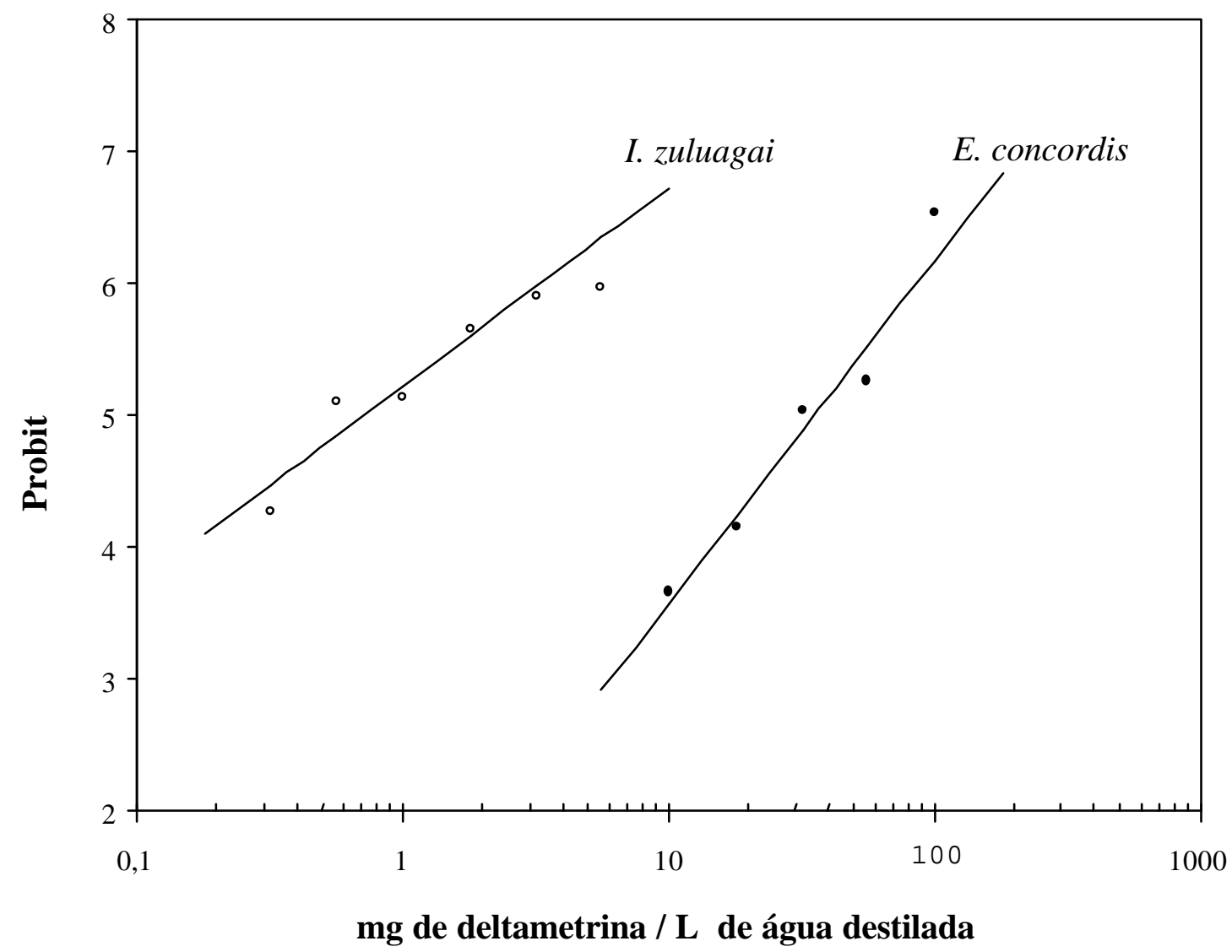

Figura 3 - Curvas de concentração-mortalidade de Euseius concordis (Ec-1) e Iphiseiodes zuluagai (Iz-1) à deltametrina. 


\subsection{Monitoramento da suscetibilidade de populações de Euseius concordis e Iphiseiodes zuluagai à deltametrina}

Os resultados referentes às respostas de diferentes populações de E. concordis e I. zuluagai à concentração de $10 \mathrm{mg}$ de deltametrina/L de água destilada [I.A. (ppm)], encontram-se representados na Figura 4.

Foram verificadas diferenças significativas na suscetibilidade entre essas espécies à deltametrina $(\mathrm{F}=122,05$; graus de liberdade $(\mathrm{g} .1)=1,.62 ; P<0,05)$, confirmando os resultados obtidos no item anterior. Evidenciou-se que E. concordis apresentou uma maior tolerância a esse produto do que I. zuluagai.

Quanto à variabilidade intraespecífica, a mesma foi observada apenas para as populações de I. zuluagai. Verificou-se que as populações coletadas em pomares abandonados (Iz-1 e Iz-2) apresentaram elevada suscetibilidade a esse produto, não sobrevivendo à concentração aplicada. No entanto, todas as populações provenientes de pomares comerciais, apresentaram porcentagem de sobrevivência superior a $45 \%$ na concentração diagnóstica utilizada (10 mg de deltametrina/L de água destilada).

Para E. concordis, verificou-se que todas as populações avaliadas apresentaram uma elevada porcentagem de sobrevivência à concentração testada, sendo observado que a sobrevivência na população Ec-1 (coletada em pomar abandonado), foi de aproximadamente 89\%. Como a concentração diagnóstica utilizada no presente monitoramente foi 3,5 vezes inferior à $\mathrm{CL}_{50}$ estimada para a população suscetível de referência (Ec-1) (35,35 mg de deltametrina/L de água destilada) por ocasião da estimativa da linha básica de suscetibilidade desta população a esse produto, o fato das populações de E. concordis terem sido mais tole rantes à concentração diagnóstica do que as populações de I. zulugai já era esperado.

Dessa forma, através dos resultados obtidos pode-se inferir que a variabilidade intraespecífica observada para as populações de I. zuluagai avaliadas foi resultante através da aplicação de inseticidas piretróides no campo, levando a um processo de seleção dos indivíduos mais adaptados nessas condições, o que justifica a presença de populações dessa espécie em algumas áreas comerciais de citros. Ainda, o fato de 
ocorrer variabilidade de resposta em campo, sugere que I. zuluagai pode ser selecionado para resistência a elevadas concentrações de piretróides em condições de laboratório.

Com relação à E. concordis, os resultados obtidos sugerem que para a detecção variabilidade intraespecífica de resposta à deltametrina, seja realizada a estimativa da $\mathrm{CL}_{50}$ para essas populações, ou então, utilizem-se concentrações diagnósticas. Nesse sentido, Halliday \& Burnham (1990) recomendaram que para diagnosticar a resistência em uma determinada população sejam usadas de duas a três concentrações que matem de 50 a 95\% dos indivíduos da população tomada como suscetível de referência.

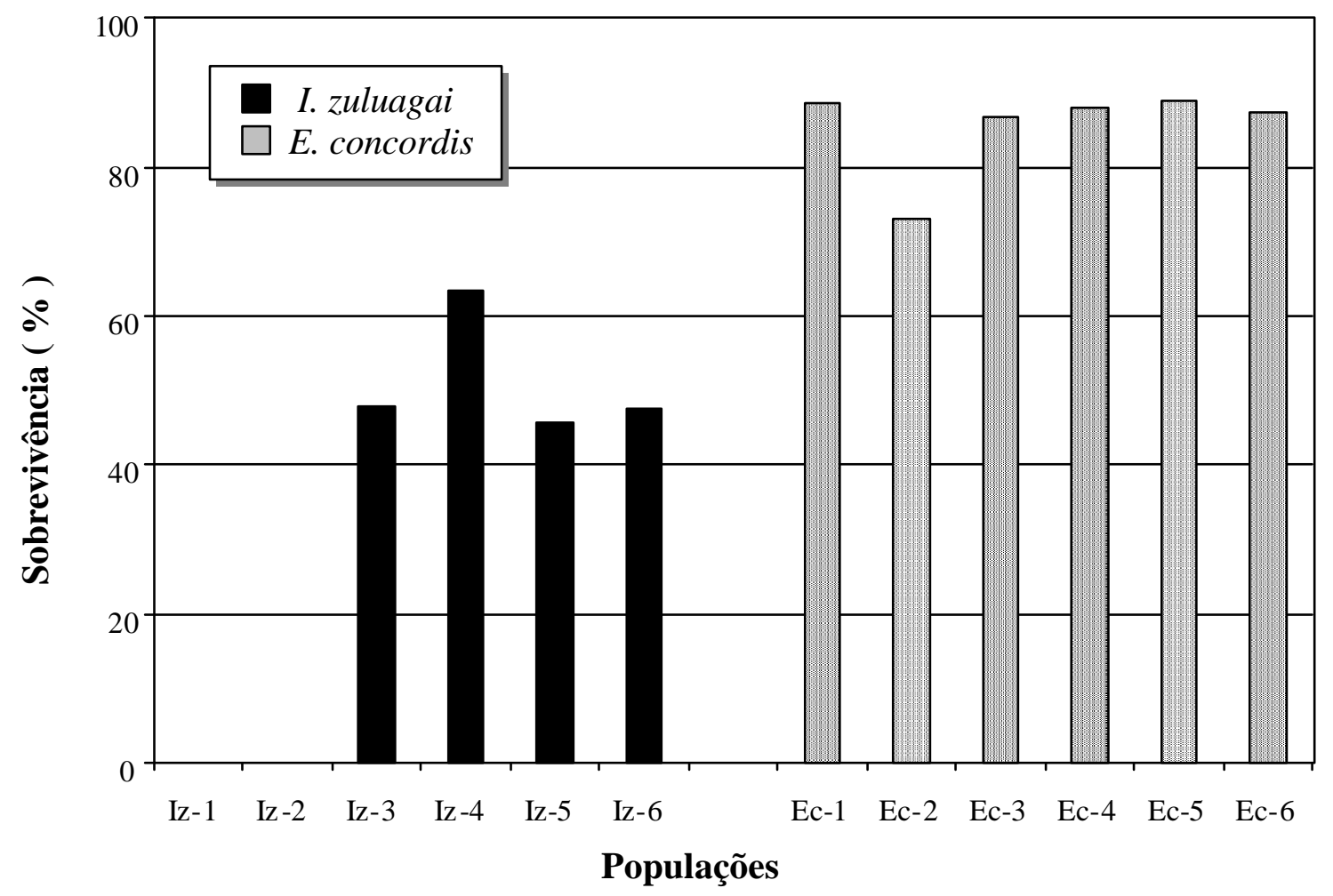

Figura 4 - Porcentagem de sobrevivência de diferentes populações de Iphiseiodes zuluagai e Euseius concordis em bioensaios para o monitoramento da suscetibilidade à concentração diagnóstica de $10 \mathrm{mg}$ de deltametrina/L de água destilada. 


\subsection{Avaliação da variabilidade intraespecífica de populações de Euseius concordis à deltametrina}

As respostas de concentração-mortalidade à deltametrina exibidas pelas populações Ec-1, Ec-2 e Ec-3 de E. concordis encontram-se representadas na Tabela 4, sendo que para isso foram testadas 505, 558 e 578 fêmeas adultas respectivamente. Para a população Ec-1, tomada como suscetível de referência, a CL50 de 35,35 mg estimada foi de deltametrina/L de água destilada [I.A. (ppm)] (I.C. 95\% 19,87-53,30), coeficiente angular ( \pm desvio padrão) de 2,60 $\pm 0,29$ e qui-quadrado $\left(\chi^{2}\right)$ de 7,85 (graus de liberdade (g.l.) = 3; P> 0,05). Com relação à população Ec-2, a CL50 estimada foi de 71,51 mg de deltametrina/L de água destilada [I.A. (ppm)] (I.C. 95\% 27,10-95,60),

coeficiente angular $\left(+\right.$ desvio padrão) de 4,02 $\pm 0,68$ e qui-quadrado $\left.\chi^{2}\right)$ de 7,90 (graus de liberdade (g.l.) $=4 ; P>0,05$ ). Para a população Ec-3 não foi possível realizar a estimativa da $\mathrm{CL}_{50}$, pois para as concentrações testadas acima de $500 \mathrm{mg}$ de deltametrina/L de água destilada [I.A.(ppm)], a mortalidade observada foi de apenas $55,36 \%$.

Observando esses dados, verifica-se que mesmo apesar da CL50 estimada para a população Ec-2 ser duas vezes superior à obtida para a população suscetível (Ec-1), não houve diferença significativa devido à sobreposição dos intervalos de confiança, estabelecidos para as $\mathrm{CL}_{50} \mathrm{~s}$ das mesmas. Porém, deve-se enfatizar que embora essas duas populações terem sido provenientes de pomares onde não se realizavam aplicações de defensivos químicos há alguns anos, ambas foram coletadas em regiões muito distantes, sendo a população Ec-1 proveniente de Presidente Prudente/SP e a população Ec-3 de Juazeiro/BA (Quadro 1). Dentro desse contexto, o isolamento geográfico pode ter interferido em alguns parâmetros biológicos, os quais foram responsáveis pela suscetibilidade diferencial observada para essas duas populações (Croft, 1990).

Noronha (2002) realizando cruzamentos e retrocruzamentos heterogâmicos, verificou incompatibilidade reprodutiva entre fêmeas de E. concordis oriundas de Petrolina/PE e machos provenientes de Arroio do Meio/RS, Jaguariúna/SP, Ponte e Lacerda/MT e Viçosa/MG, indicando o isolamento reprodutivo daquela população com 
as demais. Desse modo, devido ao município de Petrolina/PE situar-se muito próximo à Juazeiro/BA (local de origem da população Ec-2) é provável que o mesmo fato ocorra para essa população.

Num contexto prático, sugere-se que a incompatibilidade reprodutiva possa ser favorável à liberação de ácaros predadores resistentes em campo. Assim, se a linhagem selecionada para resistência a um determinado pesticida apresentar incompatibilidade reprodutiva com a população suscetível presente em campo, devido ao fato de não ocorrer cruzamentos entre a população $S$ e a linhagem $R$, não ocorrerá hibridação, podendo-se inferir nesse caso que a reversão para a suscetibilidade na linhagem resistente ocorrerá em função da estabilidade da resistência e não devido aos cruzamentos estabelecidos com a população de campo.

Tabela 4. Respostas de concentração-mortalidade de populações Ec-1, Ec-2 e Ec-3 de Euseius concordis à deltametrina.

\begin{tabular}{|c|c|c|c|c|c|c|}
\hline Populações & $\mathrm{N}^{\mathrm{a}}$ & $\begin{array}{c}\mathrm{CL}_{50}(\mathrm{mg} \mathrm{I} . \mathrm{A} . / \mathrm{L}) \\
(95 \% \mathrm{IC})\end{array}$ & $\begin{array}{c}\text { Coeficiente } \\
\text { Angular } \pm \mathrm{EP}\end{array}$ & $\chi^{2}$ & g.l. & $\mathrm{RR}^{\mathrm{b}}$ \\
\hline Ec-1 & 505 & $\begin{array}{c}35,35 \\
(19,87-53,30)\end{array}$ & $2,60 \pm 0,29$ & 7,85 & 3 & - \\
\hline Ec-2 & 558 & $\begin{array}{c}71,51 \\
(27,10-95,60)\end{array}$ & $4,02 \pm 0,68$ & 7,90 & 4 & 2,02 \\
\hline Ec-3 & 578 & $>500$ & - & - & & $>14,20$ \\
\hline
\end{tabular}


Realizando os testes de paralelismo, verificourse que as linhas de concentraçãomortalidade estimadas para as populações suscetível (Ec-1) e Ec-2 foram distintas, observando-se uma menor inclinação na reta estimada para a população suscetível $(\mathrm{Ec}-1)$.

Num contexto biológico, o coeficiente angular relaciona-se com a homogeneidade de uma determinada população, sendo que quanto maior seu valor, considera-se mais homogênea a mesma (Hoskins \& Gordon, 1956). Ainda, de acordo com ffrench-Constant \& Roush (1990) esse coeficiente também pode relacionar-se diretamente com o método de bioensaio realizado para a caracterização toxicológica de uma determinada população, podendo ser utilizado como parâmetro de adequação do mesmo. Neste trabalho, como foi utilizado o mesmo método de bioensaio para todas as populações avaliadas, a variação nesse parâmetro não deve estar relacionada à técnica de empregada. Porém, pode-se inferir que a população Ec-2 é mais homogênea do que a população $S$ (Ec-1). Uma provável justificativa, é que possa ter ocorrido um processo de seleção dos indivíduos mais adaptados nas condições de laboratório, devido ao fato da população Ec-2 ter sido mantida por um período superior às demais nessas condições.

Com relação à população Ec-3, essa foi coletada dois dias após a aplicação de deltametrina para o controle de mosca-das-frutas. Nessa ocasião, evidenciourse a presença de um grande número de ácaros fitoseídeos na área, sugerindo que os mesmos não tinham sido afetados pela pulverização desse produto, o que posteriormente foi comprovado em laboratório com os resultados obtidos. Desse modo, uma razão de resistência superior a 14 vezes (Tabela 4) foi estimada para essa população. As curvas de concentração-mortalidade obtidas para essas duas populações estão representadas na Figura 5.

Confrontando os dados do número de aplicações de piretróides realizadas na área onde foi coletada a população Ec-3 (Quadro 2), sugere-se que a evolução da resistência a esses produtos nessa espécie possa ocorrer de maneira mais rápida do que para outras espécies de ácaros fitoseídeos. Nesse sentido, Strickler \& Croft (1981) verificaram que após 21 aplicações de piretróides, realizadas num período de três anos 
em campo, a razão da resistência à permetrina em uma população de Amblyseius fallacis (Garman) chegou a aproximadamente 15 vezes.

Devido à resposta apresentada pela população Ec-3, provavelmente a mesma possa ser selecionada para resistência a elevadas concentrações de deltametrina em um curto período de tempo em condições de laboratório.

Para A. fallacis, Strickler \& Croft (1982) realizando 12 pressões de seleção em condições de casa de vegetação, obtiveram um aumento de 64 vezes na razão de resistência dessa espécie à permetrina. Em laboratório, Markwick (1986) após realizar seis pressões de seleção com cipermetrina, detectou um aumento de dez vezes na razão de resistência de T. pyri a esse produto.

Porém, deve-se ressaltar que a velocidade do aumento na razão de resistência em condições de laboratório também pode estar relacionada com o produto ou com o método de bioensaio empregado na seleção, e não somente com a espécie envolvida. Nesse sentido, Thistlewood et al. (1995) verificaram que o aumento da resistência à permetrina em uma população de A. fallacis ocorreu de maneira mais rápida e a concentrações mais elevadas através da utilização de uma técnica de bioensaio em que realizou-se a pulverização do produto em placa de Petri onde fêmeas adultas eram transferidas sobre o resíduo (Thistlewood et al., 1992). Através desse método, após 55 pressões de seleção foi possível aumentar 964 vezes a razão de resistência da população testada a esse produto. De modo contrário, esses autores verificaram que quando foi utilizado o método de mergulho de lâminas através do mesmo número de pressões de seleção, evidencioutse um aumento de apenas 3,6 vezes na razão de resistência da mesma população à permetrina.

Pelos resultados obtidos na presente pesquisa, pôde-se evidenciar a ocorrência de variabilidade nas respostas exibidas pelas populações de E. concordis à deltametrina. Desse modo, possivelmente que fato semelhante possa estar ocorrendo em outras áreas comerciais, onde estejam sendo realizadas pulverizações com esse produto.

No entanto, pelo fato de terem sido avaliadas as respostas de poucas populações neste trabalho, sugere-se que em projetos futuros sejam realizados monitoramentos da resistência em outras áreas, sendo que para isso, poderiam ser empregadas as 
concentrações diagnósticas de 35 e $150 \mathrm{mg}$ de deltametrina/L de água destilada, que correspodem às $\mathrm{CL}_{50}$ e $\mathrm{CL}_{95}$ estimadas para a população suscetível de referência (Ec-1).

Trabalhos de seleção de linhagens resistentes a elevadas concentrações de deltametrina, tomando-se inicialmente a população Ec-3, também poderiam ser realizados em projetos futuros, visto que essa espécie apresentou uma tolerância relativa a esse produto. 


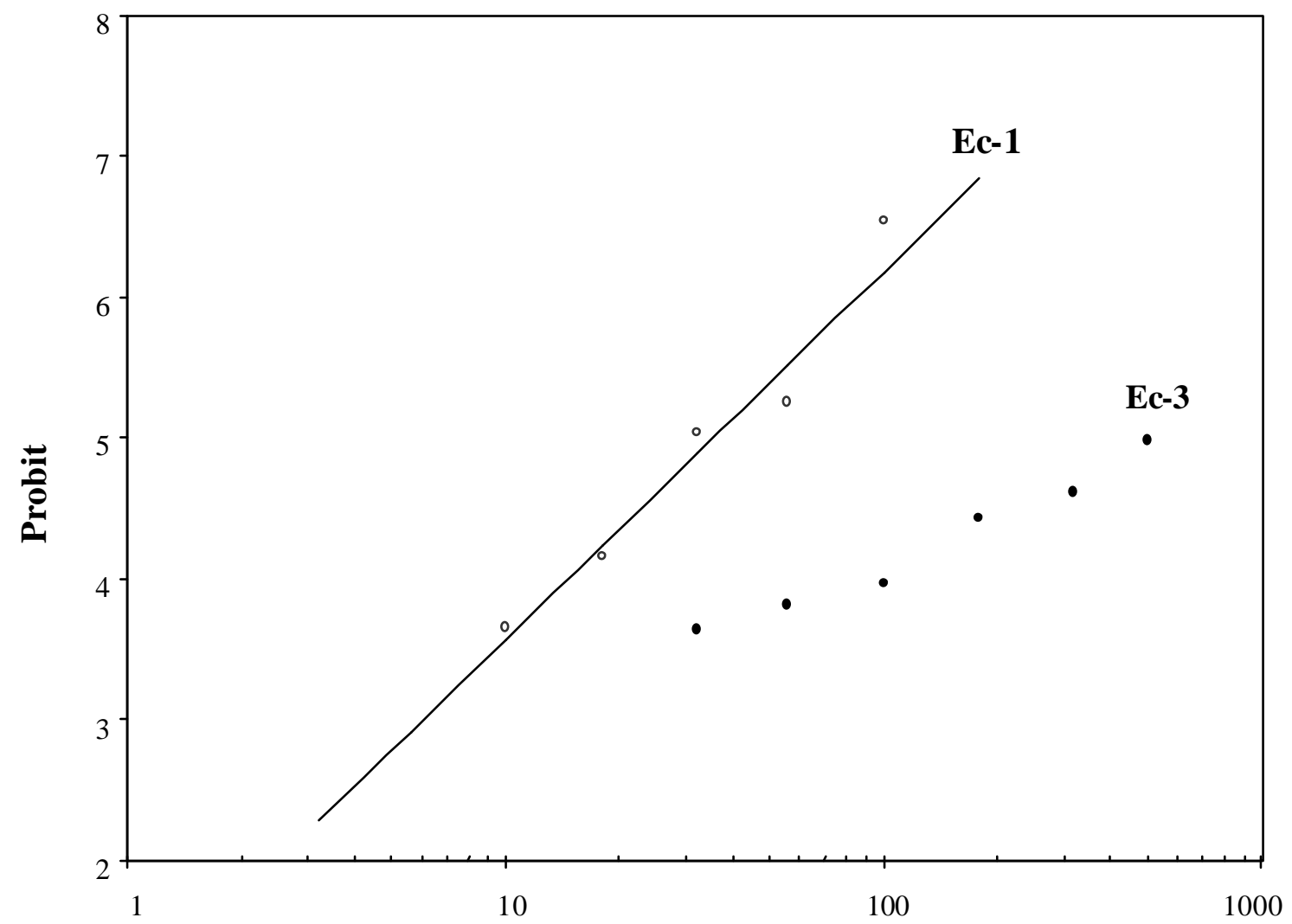

mg de deltametrina / $\mathrm{L}$ de água destilada

Figura 5 - Curvas de concentração-mortalidade das populações Ec-1 e Ec-3 de Euseius concordis à deltametrina. 


\subsection{Avaliação da variabilidade intraespecífica de populações de Iphiseiodes zuluagai à deltametrina}

As respostas de concentração-mortalidade das populações Iz-1, Iz-3, Iz-4 e Iz-6 de I. zuluagai à deltametrina encontram-se representadas na Tabela 5. Foram testadas 289, 304, 300 e 315 fêmeas adultas respectivamente.

Para a população suscetível (Iz-1), foi estimada uma CL50 de 0,71 mg de deltametrina/L de água destilada [I.A.(ppm)] (I.C. 95\% 0,32-1,14), coeficiente angular ( \pm desvio padrão) de 1,50 \pm 0,24 e qui-quadrado $\left(\chi^{2}\right)$ de 5,65 (graus de liberdade (g.1.) = 5; $P>0,05)$. Para Iz-3, a CL50 foi de 7,39 mg de deltametrina/L de água destilada [I.A.(ppm)] (I.C. 95\% 4,91-11,18), coeficiente angular ( \pm desvio padrão) de $1,40 \pm 0,19$ e qui-quadrado $\left(\chi^{2}\right)$ de 6,04 (graus de liberdade (g.1.) $=5 ; P>0,05$ ). Com relação à população Iz-4 a CL50 foi de 12,94 mg de deltametrina/L de água destilada [I.A.(ppm)] (I.C. 95\% 6,99-18,43), coeficiente angular ( \pm desvio padrão) de $2,37 \pm 0,35$ e qui-quadrado $\left(\chi^{2}\right)$ de 3,40 (graus de liberdade (g.1.) $=3 ; P>0,05$ ) E para população Iz-6, a CL50 foi de $6,61 \mathrm{mg}$ de deltametrina/L de água destilada [I.A.(ppm)] (I.C. 95\% 0,92-11,66), coeficiente angular ( \pm desvio padrão) de $1,87 \pm 0,38$ e qui-quadrado $\left(\chi^{2}\right)$ de 10,32 (graus de liberdade (g.l.) $=4 ; P>0,05$ ).

Pelos resultados obtidos, observa-se que há variabilidade intraespecífica de resposta à deltametrina com relação às populações de I. zuluagai avaliadas. Verificou-se que as populações Iz-3 e Iz-4 diferiram da população suscetível (Iz-1), devido à não sobreposição dos intervalos de confiança estimados para as $\mathrm{CL}_{50} \mathrm{~s}$. Ainda, através do teste de paralelismo e igualdade, verificou-se que as linhas de regressão estimadas para ambas populações foram consideradas dis tintas com relação à obtida para a população suscetível (Iz-1). Dessa forma, foram estimadas razões de resistência (RR) de aproximadamente 10 vezes para a população Iz-3 e 18 vezes para a população Iz-4 (Tabela 5). Na Figura 6 encontram-se representadas as curvas de concentraçãomortalidade estimadas para as populações suscetível (Iz-1) e Iz-4. 
Tabela 5. Respostas de concentração-mortalidade de populações Iz-1, Iz-3, Iz-4 e Iz-6 de Iphiseiodes zuluagai à deltametrina.

\begin{tabular}{|c|c|c|c|c|c|c|}
\hline Populações & $\mathrm{n}^{\mathrm{a}}$ & $\begin{array}{c}\mathrm{CL}_{50} \text { (mg I. A./L) } \\
(95 \% \text { IC) }\end{array}$ & $\begin{array}{c}\text { Coeficiente } \\
\text { Angular } \pm \text { EP }\end{array}$ & $\chi^{2}$ & g.l. & $\mathrm{RR}^{\mathrm{b}}$ \\
\hline Iz-1 & 289 & $\begin{array}{c}0,71 \\
(0,32-1,14)\end{array}$ & $1,50 \pm 0,24$ & 5,65 & 5 & - \\
\hline Iz-3 & 304 & $\begin{array}{c}7,39 \\
(4,91-11,18)\end{array}$ & $1,40 \pm 0,19$ & 6,04 & 5 & 10,41 \\
\hline Iz-4 & 300 & $\begin{array}{c}12,94 \\
(6,99-18,43)\end{array}$ & $2,37 \pm 0,35$ & 3,40 & 3 & 18,23 \\
\hline Iz- 6 & 315 & $\begin{array}{c}6,61 \\
(0,92-11,66)\end{array}$ & $1,87 \pm 0,38$ & 10,32 & 4 & 9,31 \\
\hline
\end{tabular}

${ }^{a}$ Número de ácaros testados

${ }^{\mathrm{b}} \mathrm{RR}=$ Razão de Resistência: $\mathrm{CL}_{50}$ população em estudo / CL $\mathrm{L}_{50}$ população suscetível (Iz-1)

Do mesmo modo que o observado para a população Ec-3 de E. concordis, a evolução da resistência desenvolvida pelas populações Iz-3 e Iz-4 em campo, ocorreu de maneira relativamente rápida, sendo que as mesmas foram submetidas a duas e três aplicações de piretróides, respectivamente, em um período de três anos (Quadro 2).

Como a $\mathrm{CL}_{50}$ estimada para a população Iz-4 apresentou-se muito próxima à concentração recomendada para o controle de insetos-praga em campo $(12,5 \mathrm{mg}$ de deltametrina/L de água), sugere-se que provavelmente nessa área, a densidade populacional dessa espécie esteja sendo menos afetada pela aplicação de inseticidas piretróides do que nas áreas onde foram coletadas as demais populações avaliadas.

Com relação à população Iz-6, verificou-se que apesar dessa ter apresentado uma $\mathrm{CL}_{50}$ nove vezes superior à obtida para a população suscetível (Iz-1), não ocorreu diferença significativa entre as mesmas devido à sobreposição dos intervalos de confiança estimados para ambas. No entanto, verificourse através do teste de igualdade, 
que embora as linhas de regressão dessas populações terem sido paralelas, essas foram consideradas distintas. Provavelmente a evolução da resistência à deltametrina nessa população possa ocorrer em uma velocidade relativamente rápida, caso a mesma seja submetida a uma pressão de seleção, que poderá ser exercida tanto em condições de campo como de laboratório.

Nesse sentido, a evolução da resistência em populações dessa espécie, é extremamente desejável devido ao fato da mesma apresentar uma elevada suscetibilidade a esse produto em campo. Desse modo, da mesma forma que o sugerido anteriormente para E. concordis, pelo fato de terem sido avaliadas as respostas de poucas populações dessa espécie, sugere-se que futuramente sejam realizados monitoramentos da resistência em outras áreas, empregando-se nesse caso as concentrações diagnósticas de 0,7 e 9,0 mg de deltametrina/L de água destilada, correspondentes às $\mathrm{CL}_{50}$ e $\mathrm{CL}_{95}$ estimadas para a população suscetível (Iz-1). A utilização de concentrações diagnósticas tem sido considerado um dos caminhos mais acessíveis para a detecção da resistência (ffrench-Constant \& Roush, 1990), tanto para insetos e ácaros-pragas quanto para os inimigos naturais. 


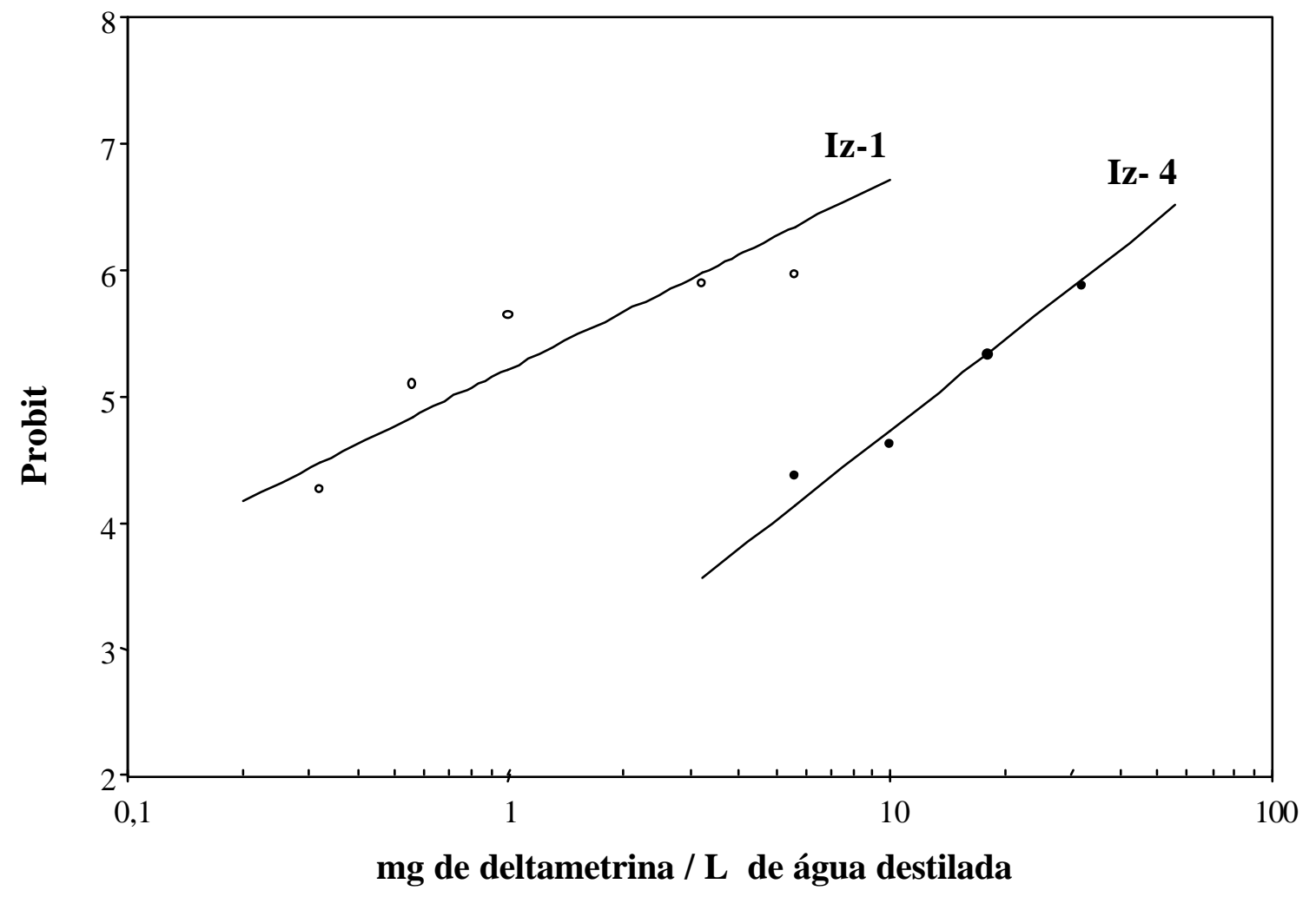

Figura 6 - Curvas de concentração-mortalidade das populações Iz-1 e Iz-4 de Iphiseiodes zuluagai à deltametrina 


\subsection{Avaliação da variabilidade nas respostas de repelência à deltametrina nas populações Ec-1 e Ec-3 de Euseius concordis}

Os resultados obtidos nesse bioensaio encontram-se representados na Tabela 6. Foram avaliadas as respostas de 242 e 350 fêmeas adultas das populações Ec-1 e Ec-3 de E. concordis respectivamente. Para a população suscetível à deltametrina (Ec-1) foi estimada uma $\mathrm{CRep}_{50}$ de 17,03 mg de deltametrina/L de água destilada [I.A. (ppm)] (I.C. 95\% 4,99-59,26), coeficiente angular ( \pm desvio padrão) de 0,84 $\pm 0,18$ e qui-quadrado $\left(\chi^{2}\right)$ de 10,44 (graus de liberdade (g.1.) $=4 ; P>0,05$ ). Com relação à população Ec-3, não foi possível realizar a estimativa da CRep50 para a mesma, pois na maior concentração testada, $3200 \mathrm{mg}$ de deltametrina/L de água destilada [I.A.(ppm)], a repelência de apenas $24 \%$ dos indivíduos avaliados. Na Figura 7 podem ser evidenciadas as curvas de concentração-repelência estimadas para ambas populações avaliadas.

Através da divisão da concentração mais alta testada para a população Ec-3 (3200 mg de deltametrina/L de água destilada) pela CRep50 estimada para a população Ec-1, obteve-se uma razão de repelência (RRep), através da qual pôde-se evidenciar que esse produto apresentou uma repelência maior que 188 vezes para a população Ec-1 do que para a Ec-3. Dessa forma as respostas exibidas por essas populações sugerem que a resistência nesse caso, provavelmente esteja envolvida com um mecanismo fisiológico e não comportamental, devido ao fato dos indivíduos da população Ec-3, não exibirem um comportamento de dispersão com intuito de evitar o resíduo do produto.

$\mathrm{Na}$ prática, a deltametrina apresenta um elevado efeito de repelência sobre os ácaros fitófagos como Tetranychus urticae Koch (Penman et al., 1986). Dessa forma, somado ao efeito negativo dos piretróides sobre os ácaros predadores, que geralmente apresentam elevada suscetibilidade a esses produtos, o efeito de repelência sobre os ácaros fitófagos também pode ser responsável pelo desequilíbrio ecológico em um agroecosistema (Gerson \& Cohen, 1989).

Através do comportamento de dispersão exibidos pelos ácaros fitófagos, com intuito de emigrar para áreas não-tratadas (Iftner \& Hall, 1983), pode ocorrer uma 
escassez de alimento para os ácaros predadores, principalmente para espécies consideradas especialistas (McMurtry, 1997) ou que apresentam baixa capacidade de dispersão.

No presente estudo, verificourse que a população Ec-1 quando submetida à concentração de $10 \mathrm{mg}$ de deltametrina/L de água destilada (concentração testada que mais se aproximou da concentração recomendada de $12,5 \mathrm{mg}$ de deltametrina/L de água destilada), exibiu repelência superior a 30\%. Assim, a emigração desses indivíduos para áreas não-tratadas, poderá coincidir com a dispersão dos ácaros fitófagos como B. phoenicis, em direção ao mesmo local, ocorrendo dessa forma uma razoável disponibilidade de alimento para esses predadores.

Com relação à população Ec-3 (resistente à deltametrina), ou mesmo outros indivíduos remanescentes das população Ec-1 que permanecerem sobre o resíduo do produto, esses poderão se alimentar de fontes alternativas como fungos ou pequenos insetos (na ausência do ácaro fitófago), já que os ácaros do gênero Euseius são considerados generalistas quanto ao hábito alimentar (McMurtry et al., 1992; McMurtry, 1997; Zhao \& McMurtry, 1990).

Tabela 6. Respostas de concentração-repelência das populações Ec-1 e Ec-3 de Euseius concordis à deltametrina.

\begin{tabular}{ccccccc}
\hline População & $\mathrm{n}^{\text {a }}$ & $\begin{array}{c}\text { CRep 50 (mg I. A./L) } \\
\text { (95\% IC) }\end{array}$ & $\begin{array}{c}\text { Coeficiente } \\
\text { Angular } \pm \text { EP }\end{array}$ & $\chi^{2}$ & g.l. & RRep $^{\text {b }}$ \\
\hline Ec-1 & 242 & $\begin{array}{c}17,03 \\
(4,99-59,26)\end{array}$ & $0,84 \pm 0,18$ & 10,44 & 4 & - \\
& & & & & & \\
Ec-3 & 350 & $>3200$ & - & - & - & $>187,90$ \\
\hline
\end{tabular}

\footnotetext{
${ }^{a}$ Núme ro de ácaros testados

${ }^{\mathrm{b}} \mathrm{Rr}$ = Razão de Repelência: maior concentração testada para a população $\mathrm{R} / \mathrm{CR}_{50}$ da população $\mathrm{S}$
} 


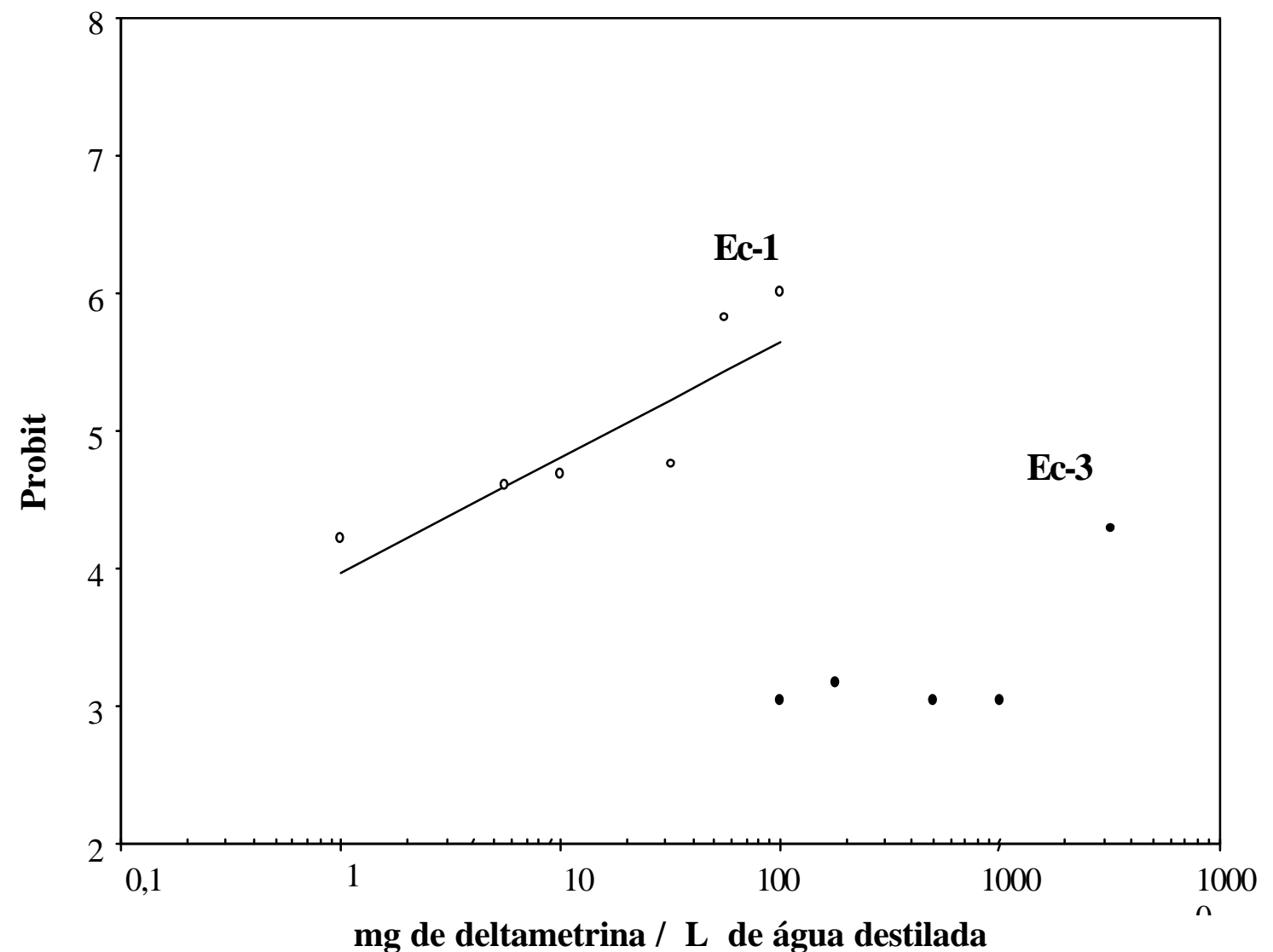

Figura 7 - Curvas de concentração-repelência das populações suscetível (Ec-1) e Ec-3 de Euseius concordis à deltametrina. 


\subsection{Considerações finais}

Pelos resultados obtidos, verifica-se que o controle químico de ácaros e insetospragas na cultura dos citros pode exercer um efeito negativo sobre a densidade populacional dos ácaros fitoseídeos, importantes inimigos naturais do ácaro-da-leprose nessa cultura. Nesse sentido, a ressurgência dessa praga em algumas áreas pode estar relacionada à utilização de produtos químicos não seletivos a esses predadores como o acaricida dicofol e o inseticida deltametrina. Dentro desse contexto, verificou-se que apesar de não ocorrer variabilidade nas resposta exibidas por A. chiapensis, E. concordis e I. zuluagai ao dicofol, suscetibilidade diferencial à deltametrina foi observada entre E. concordis e I. zuluagai, sendo que a primeira espécie apresentou uma tolerância 50 vezes superior à estimada para I. zuluagai.

O fato de também não ter sido observada variabilidade intraespecífica de resposta ao acaricida dicofol, possivelmente tenha ocorrido devido ao reduzido número de populações de E. concordis avaliadas, sendo que a única proveniente de pomar comercial foi coletada em uma área, onde segundo informações concedidas pelo proprietário, a utilização de produtos químicos para o controle de ácaros não era freqüente.

Por outro lado, com relação à deltametrina evidenciou-se a ocorrência de variabilidade intraespecífica tanto para as populações de E. concordis como I. zuluagai. Desse modo, pode-se inferir que apesar do produto apresentar um efeito nocivo à I. zuluagai, populações dessa espécie têm sido selecionadas para resistência em condições de campo, sendo que a evolução da mesma tem ocorrido de maneira relativamente rápida. Assim, devido à presença desses inimigos naturais nessas áreas,

provavelmente os problemas ocasionados pelo ácaro-da-leprose encontrem-se amenizados devido ao controle biológico exercidos por esses organismos.

Observando as respostas apresentadas pelas populações Ec-3 de E. concordis, Iz-3 e Iz-4 de I. zuluagai, sugere-se que através de um processo de pressão de seleção em laboratório, possam ser obtidas linhagens resistentes dessas duas espécies a elevadas concentrações de deltametrina, que liberadas em campo provavelmente sobreviveriam às 
pulverizações realizadas com esse inseticida. Porém, dentro do ponto de vista prático, a multiplicação massal de E. concordis e I. zuluagai é tida como um entrave para a liberação dos mesmos em campo com intuito de implementar o controle biológico do ácaro-da-leprose em citros no Brasil, pois até o presente momento essas espécies foram mantidas apenas em criações de pequena escala para o desenvolvimento de pesquisas em laboratório.

Um aspecto interessante que poderia ser abordado em futuros projetos de pesquisa, poderia estar relacionado à seleção de novas espécies de ácaros predadores promissoras no controle biológico de B. phoenicis para introdução na cultura dos citros. De acordo com Moraes \& Sá (1995) provavelmente algumas espécies de fitoseídeos encontradas em pomares de citros na Flórida poderiam ser investigadas com esse propósito, pois além de ocorrerem semelhanças climáticas desse local com o Sudeste do Brasil, o ácaro-da-leprose também está presente nesse Estado norte americano. Porém, deve-se enfatizar que estudos preliminares para avaliar parâmetros tais como a capacidade de predação dessas espécies sobre $B$. phoenicis e a suscetibilidade das mesmas a pesticidas comumente utilizados na cultura dos citros devem ser realizados. Ainda, recomenda-se que pesquisas também sejam conduzidas com intuito de avaliar a possibilidade de ocorrer um impacto negativo causado pela liberação dessas novas espécies de fitoseídeos sobre a densidade populacional de E. citrifolius, E. concordis, I. zuluagai, dentre outras espécies comumente encontradas nos pomares de citros no Brasil. 


\section{CONCLUSÕES}

Para as populações de ácaros fitoseídeos avaliadas no presente estudo, pode-se concluir que:

- Não há variabilidade interespecífica na suscetibilidade de Amblyseius chiapensis DeLeon, Euseius concordis (Chant) e Iphiseiodes zuluagai Denmark \& Muma ao dicofol.

- Não há variabilidade intraespecífica na suscetibilidade de populações de E. concordis ao dicofol.

- E. concordis é mais tolerante à deltametrina do que I. zuluagai.

- Há variabilidade intraespecífica na suscetibilidade de populações de E. concordis e I. zuluagai à deltametrina.

- Há variabilidade intraespecífica nas respostas de repelência à deltametrina em populações de E. concordis. 


\section{REFERÊNCIAS BIBLIOGRÁFICAS}

ALINIAZEE, M. T.; CRANHAM, J. E. Effect of four synthetic pyrethroids on a predatory mite, Typhlodromus pyri and its prey, Panonychus ulmi, on apples in Southeast England. Environmental Entomology, v.9, n.4, p.436-439, 1980.

BAKER, J. E.; ARBOGAST, R. T. Malathion resistance in field strain of warehouse pirate bug (Heteroptera: Anthocoridae) and a prey species Tribolium castaneum (Coleoptera: Tenebrionidae). Journal of Economic Entomology, v.88, n.2, p.241$45,1995$.

BLACKWOOD, J. S.; SCHAUSBERGER, P.; CROFT, B. A. Prey-stage preference in generalist and specialist phytoseiidae mites (Acari: Phytoseiidae) when offered Tetranychus urticae (Acari: Tetranychidae) eggs and larvae. Environmental Entomology, v.30, n.6, p.1103-1111, 2001.

BLOMMERS, L. H. M. Integrated pest management in European apple orchards. Annual Review of Entomology, v.39, p.213-241, 1994.

CHANT, D. A. The Phytoseiidae: external anatomy. In: HELLE, W.; SABELIS, M. W. (Ed.) Spider mites: their biology, natural enemies and control. Amsterdam: Elservier, 1985a. v.1B, p.5-9. 
CHANT, D. A. The Phytoseiidae: systematics and morphology. In: HELLE, W.; SABELIS, M. W. (Ed.) Spider mites: their biology, natural enemies and control, Amsterdam: Elservier, 1985b. v.1B, p.3.

CHIARADIA, L. A.; CRUZ, F. Z. da. Seletividade de acaricidas a artrópodes benéficos em citros. Agropecuária Catarinense, v.10, n.2, p.62-65, 1997.

CHILDERS, C. C.; AGUILAR, H.; VILllanUEVA, R.; ABOU-SETTA, M. M. Comparative residual toxicities of pesticides to the predator Euseius mesembrinus (Acari: Phytoseiidae) on citrus in Florida. Florida Entomologist, v.84, n.3, p.391401, 2001.

CROFT, B. A. Arthropod biological control agents and pesticides. New York: Wiley Interscience, 1990.723p.

CROFT, B. A.; BARNES, M. M. Comparative studies on four strains of Typhlodromus occidentalis. Persistence of insecticide-resistant strains in an apple orchard ecosystem. Journal of Economic Entomology, v.65, n.1, p.21-216, 1972.

CROFT, B. A.; DUNLEY, J. E. Habitat patterns and pesticide resistance. In: KIM, K. C.; McPHERON, B. A. Evolution of insect pests: patterns of variations. New York: Jonh Wiley and Sons INC, 1993. p.145-162.

CROFT, B. A.; MORSE, J. G. Research advances on pesticides resistance in natural enemies. Entomophaga, v.24, p.3-11,1979.

CROFT, B. A.; WHALON, M. E. Selective toxicity of pyrethroid insecticides to arthropod natural enemies and pests of agricultural crops. Entomophaga, v.27, n.1, p.3-21, 1982. 
CROFT, B. A.; WHALON, M. E. Inheritance and persistence of permethrin resistance in the predatory mite Amblyseius fallacis (Acarina: Phytoseiidae). Environmental Entomology, v.12, p.215-218, 1983.

CROFT, B. A.; BROWN, A. W.; HOYING, S. A. Organophosphorus-resistance and its inheritance in the predaceous mite Amblyseius fallacis. Journal of Economic Entomology, v.69, n.1, p.64-68, 1976.

FFRENCH-CONSTANT, R. H.; ROUSH, R. T. Resistance detection and documentation: the relative roles of pesticidal and biochemical assays. In: ROUSH, R. T.; TABASHINIK, B. E. (Ed.). Pesticide resistance in arthropods. New York: Chapman and Hall, 1990. cap.2, p.4-38.

FITZGERALD, J. D.; SOLOMON, M. G. Field selection of predatory mite Typhlodromus pyri for resistance to pyrethroids. Crop Protecion, v.11, p.11991204, 1992.

FNP CONSULTORIA \& COMÉRCIO. Agrianual 2002: anuário estatístico da agricultura brasileira. São Paulo, 2002. p.285-315: Citros/laranja.

FOURNIER, D.; PRALAVORIO, M.; COULON, J.; BERGE, J. B. Fitness comparison in Phytoseiulus persimilis strains resistant and suscetible to methidathion. Experimental and Applied Acarology, n.5, p.55-64, 1988.

FURTADO, I.P.; MORAES, G. J. de. Biology of Euseius citrifolius, a candidate for the biological control of Mononychellus tanajoa (Acari: Phytoseiidae, Tetranychidae). Systematic and Applied Acarology, n.3, p.43-48, 1998. 
GEORGHIOU, G. P. Management of resistance in arthropods. In: GEORGHIOU, G. P.; SAITO, T. (Ed.) Pest resistance to pesticides. New York: Plenum, 1983. p.769-792.

GEORGHIOU, G. P.; LAGUNES-TEJEDA, A. The occurrence of resistance to pesticides in arthropods. Rome: FAO, 1991. 318p.

GERSON, U.; COHEN, E. Resurgences of spider mites (Acari: Tetranychidae) induced by synthetic pyrethroids. Experimental and Applied Acarology, v.6, p.29-46, 1989.

GRAVENA, S. Manejo ecológico de pragas no pomar cítrico. Laranja, v.11, n.1, p.205$225,1990$.

GRAVENA, S. Manejo Ambiental de Pragas dos Citros. Laranja, n.12, p. 247-88, 1991.

GRAVENA, S. Rotação de acaricidas no MIP-Citros: menos desequilíbrio e resistência. Laranja, v.15, n.2, p.375-395, 1994.

GRAVENA, S. Manejo das cigarrinhas e CVC no pomar. In: DONADIO, L. C.; MOREIRA, C. S. (Ed.) Clorose variegada dos citros. Bebedouro: Fundecitrus, E.E. Citricultura de Bebedouro, 1997. p. 92-113.

GRAVENA, S.; BENETOLI, I.; MOREIRA, H. R. P.; YAMAMOTO, P. T. Euseius citrifolius DENMARK \& MUMA predation on citrus leprosis mite Brevipalpus phoenicis (Geijskes) (Acari: Phytoseiidae: Tenuipalpidae). Anais da Sociedade Entomológica do Brasil, v.23, n.2, p.20-18,1994. 
GUIRADO, N.; SILVERIO, J. L. Leprose e declínio: problemas sérios da citricultura paulista. Laranja, v.13, n.2, p.541-552, 1992.

HADAM, J. J.; ALINIAZEE, M. T.; CROFT, B. A. Phytoseiid mites (Parasitiformes: Phytoseiidae) of major crops in Willamett Valley, Oregon, and Pesticide Resistance in Typhlodromus pyri Scheuten. Environmental Entomology, v.15, n.6, p.12551263, 1986.

HALliDAY, W. R.; BURNHAM, K. P. Choosing the optimal diagnostic dose for monitoring insecticide resistance. Journal of Economic Entomology, v.83, p.1151$1159,1990$.

HARDMAN, J. M.; ROGERS, R. E. L.; MACLELLAN, C. R. Advantages and disadvantages of using pyrethroids in Nova Scotia apple orchards. Journal of Economic Entomology, v.81, p.1737-1749, 1988.

HARDMAN, J. M.; ROGERS, M. L.; GAUL, S. O.; BENT, E. D. Insectary rearing and initial testing in Canada of an organofosfate/pyrethroid-resistant strain of predator mite Typhlodromus pyri (Acari: Phytoseiidae) from New Zealand. Environmental Entomology, v.26, n.6, p.1424-1436, 1997.

HARDMAN, J. M.; ROGERS, R. E. L.; NYROP, J. P.; FRISCH, T. Effect of pesticide applications on abundance of European red mite (Acari: Tetranychidae) and Typhlodromus pyri (Acari: Phytoseiidae) in Nova Scotian apple orchards. Journal of Economic Entomology, v.84, n.2, p.570-580, 1991.

HARDMAN, J. M.; MOREAU, D. L.; SNYDER, M.; GAUL, S. O.; BENT, E. D. Performance of a pyrethroid-resistant strain of the predator mite Typhlodromus pyri (Acari: Phytoseiidae) under diferent insecticide regimes. Journal of Economic Entomology, v.93, n.3, p.590-604, 2000. 
HOSKINS, W. M.; GORDON, H. T. Arthropod resistance to chemicals. Annual Review of Entomology, v.1, p.89-122, 1956.

HOY, M. A. Integrated mite management for California almond orchards. In: HELLE, W.; SABELIS, M. W. (Ed.) Spider mites: their biology, natural enemies and control, Amsterdam: Elservier, 1985a., v.1B, p.299-310.

HOY, M. A. Recents advances in genetics and genetic improvement of the Phytoseiidae. Annual Review of Entomology, v.30, p.347-370, 1985b.

HOY, M. A.; KNOP, N. F. Selection for and genetic analysis of permethrin resistance in Metaseiulus occidentalis: genetic improvement of biological control agent. Entomologia Experimentalis et Applicata, v.30, p.10-18, 1981.

HOY, M. A.; OUYANG, Y. Selectivity of the acaricides clofentezine and hexythiazox to the predator Metaseilus occidentalis (Aari: Phytoseiidae). Journal of Economic Entomology, v.79, n.5, p.1377-1380, 1986

HOY, M. A.; WESTIGARD, P. H.; HOYT, S. C. Release and evaluation of a laboratory-selected, pyrethroid-resistant strain of the predaceous mite Metaseiulus occidentalis (Acari: Phytoseiidae) in Southern Oregon pear orchards and a Whashington apple orchard. Journal of Economic Entomology, v.76, n.2, p.383$388,1983$.

HOY, M. A.; VAN DE BAAN, H. E.; GROOT, J. J. R.; FIELD, R.P. Aerial movements of mites in almonds: implications for pest management. California Agriculture, v.38, n.9, p.21-23, 1984.

HOYT, S. C. Integrated chemical control of insects and biological control of mites on apple in Washington. Journal of Economic Entomology, v.62, p.74-86, 1969. 
HOYT, S. C.; WESTIGARD, P. H.; BURTS, E. C. Effects of 2 synthetics pyrethroids on the codling moth, pear psylla and various mite species in Northwest apple and pear orchards. Journal of Economic Entomology, v.71, p.431-434, 1978.

IFTNER, D. C.; HALL, F. R. Effects of fenvalerate and permethrin on Tetranychus urticae Koch (Acari: Tetranychidae) dispersal behavior. Environmental Entomology, v.12, n.6, p.1782-1786, 1983.

JACOBSON, R. J.; CROFT, P.; FENLON, J. Response to fenbutatin oxide in populations of Tetranychus urticae Kock (Acari: Tetranychidae) in UK protect crops. Crop Protection, v.18, n.1, p.47-52, 1999.

JEPPSON, L. R.; KEIFFER, H. H.; BAKER, E. W. Mites injurious to economic plants. Berkeley: University of California, 1975. 614p.

KENNETT, C. E. Resistance to parathion in Phytoseiidae mite Amblyseius hibisci. Journal of Economic Entomology, v.63, n.6, p.1999-2000, 1970.

KOGAN, M. Integrated pest management: Historical perspectives and contemporary developments. Annual Review of Entomology, v.43, p.243-270, 1998.

KOMATSU, S. S.; NAKANO, O. Estudos visando o manejo do ácaro da leprose em citros através do ácaro predador Euseius concordis (Acari: Phytoseiidae). Laranja, v.9, n.1, p.125-146, 1988.

KOSTIAINEN, T.; HOY, M. A. Variability in resistance to organophosphorous insecticides in field-collected colonies of Amblyseius finlandicus (Oudemans) (Acari: Phytoseiidae). Journal of Applied Entomology, v.117, p.370-379, 1994a. 
KOSTIAINEN, T.; HOY, M. A. Genetic improvement of Amblyseius finlandicus (Acari: Phytoseiidae): laboratory selection for resistance to azinphosmetil and dimethoate. Experimental and Applied Acarology, v.18, p.469-484, 1994b.

\section{KOSTIAINEN, T.; HOY, M. A. The Phytoseiidae as biological control agents of pest} mites and insects: a bibliography. Gainesville: University of Florida, 1996. 355p.

LEORA SOFTWARE. POLO-PC: a user`s guide to Probit or logit analysis. Berkeley, 1987. 20p.

LOFEGO, A. C. Caracterização morfológica e distribuição geográfica da espécies de Amblyseiinae (Acari: Phytoseiidae) no Brasil. São Paulo, 1998. 167p. Dissertação (Mestrado) - Instituto de Biociências, Universidade de São Paulo.

MALEZIEUX, S.; LAPCHIN, L.; PRALAVORIO, M.; MOULIN, J. C.; FOURNIER, D. Toxicity of pesticide residues to a beneficial arthropod, Phytoseiulus persimilis (Acari: Phytoseiidae). Journal of Economic Entomology, v.85, n.6, p.2077-2081, 1992.

MARKWICK, N. P. Detecting variability and selecting for pesticide resistance into two species of Phytoseiidae mites. Entomophaga, v.31, n.3, p.225-236, 1986.

MARSHALL, D. B.; THISTLEWOOD, H. M. A.; LESTER, P. J. Release, establishment, and movement of the predator Typhlodromus pyri (Acari: Phytoseiidae) on apple. The Canadian Entomologist, v.133, p.279-292, 2001.

McMUTRY, J. A. Life-styles of Phytoseiidae mites and their holes in biological control. Annual Review of Entomology, v.42, p. 291-321, 1997. 
McMUTRY, J. A.; MORSE, J. G.; JOHNSON, H. G. Studies of the impact of Euseius species (Acari: Phytoseiidae) on citrus mites using predator exclusion and predator release experiments. Experimental and Applied Acarology, v.15, p.233-248, 1992.

McMURTRY, J. A.; SCRIVEN, G.T. Insectary production of phytoseiid mites. Journal of Economic Entomology, v.58, n.2, p.282-284, 1965.

MOCHIZUKI, M. Variations in insecticide susceptibility of predatory mite, Amblyseius womersleyi Schicha (Acarina: Phytoseiidae) in tea fields of Japan. Applied Entomology and Zoology, v.29, n.2, p.203-209, 1994.

MONTEIRO, L. B. Seletividade de inseticidas a Neoseiulus californicus McGregor (Acari: Phytoseiidae) em macieira, no Rio Grande do Sul. Revista Brasileira de Fruticultura, v.23, n.3, p.589-592, 2001.

MORAES, G. J. de. Controle biológico de ácaros fitófagos. Informe Agropecuário, v.15, n.167, p. 56-62, 1991.

MORAES, G. J. de. Perspectivas para o uso de predadores no controle de ácaros fitófagos no Brasil. Pesquisa Agropecuária Brasileira, v.27, p.263-270, 1992.

MORAES, G. J. de. Controle de qualidade de ácaros Phytoseiidae (Acari) para o uso em controle biológico de ácaros pragas. In: BUENO, V. H. P. (Ed.), Controle biológico de pragas: produção massal e controle de qualidade. Lavras: Editora UFLA, 2000. p.57-67.

MORAES, G. J. de; LIMA, H. C. Biology of Euseius concordis (Chant) (Acarina: Phytoseiidae) a predator of tomato russet mite. Acarologia, v.24, n.3, p.251-255, 1983. 
MORAES, G. J. de.; MCMUTRY, J. A. Biology of Amblyseius citrifolius (Denmark \& Muma) (Acari: Phytoseiidae). Hilgardia, v.49, n.1, p.1-29, 1981.

MORAES, G. J. de; SÁ, L. A. N. de. Perspectivas do controle do ácaro da leprose em citros. In: OLIVEIRA, C. A. L. de; DONADIO, L. C. (Ed.). Leprose dos citros, Jaboticabal: FUNEP, 1995. p.117-128.

MORAES, G. J. de; McMURTRY, J. A., DENMARK, H A. A catalog of the mite family Phytoseiidae: references to taxonomy, synonymy, distribution and habitat. Brasília: EMBRAPA-DDT, 1986. 353p.

MOREIRA, P. H. R. Ocorrência, dinâmica populacional de ácaros predadores em citros e biologia de Euseius citrifolius (Acari: Phytoseiidae). Jaboticabal, 1993. 110p. Dissertação (Mestrado) - Faculdade de Ciências Agrárias e Veterinárias, Universidade Estadual Paulista "Júlio de Mesquita Filho".

MOREIRA, P. H. R.; YAMAMOTO, P. T.; GRAVENA, S. Toxicidade à Iphiseiodes zuluagai Denmark \& Muma (Acari: Phytoseiidae) em citros. In: CONGRESSO BRASILEIRO DE ENTOMOLOGIA, 14. Piracicaba, 1993. Resumos. Piracicaba: SEB, 1993. p.727.

MORSE, J. G.; BELLOWS, T. S.; GASTON, L. K.; IWATA, Y. Residual toxicity to three beneficials species on California citrus. Journal of Economic Entomology, v.80, n.4, p.953-960, 1987.

NEVES, M. E.; DRAGONE, D. Z.; DAYOUB, M. Demanda por defensivos na citricultura: análise comparativa com outras culturas comerciais. Laranja, v.22, n.2, p.285-297, 2001. 
NORONHA, A. C. S. Caracterização morfológica e molecular de ácaros predadores do gênero Euseius (Acari: Phytoseiidae). Piracicaba, 2002. 110p. Tese (Doutorado) Escola Superior de Agricultura "Luiz de Queiroz", Universidade de São Paulo.

OMOTO, C. Manejo da resistência de ácaros e insetos aos produtos químicos na citricultura. Laranja, v.16, n.1, p.187-208, 1995.

OMOTO, C.; ALVES, E. B.; RIBEIRO, P. C. Detecção e monitoramento da resistência de Brevipalpus phoenicis (Geijskes) (Acari: Tenuipalpidae) ao dicofol. Anais da Sociedade Entomológica do Brasil, v.29, n.4, p.757-764, 2000.

PAPA, G.; SANTOS, M. C.; NAKANO, O. Ação de alguns acaricidas sobre os inimigos naturais presentes em um pomar de citros. In: CONGRESSO BRASILEIRO DE ENTOMOLOGIA, 13. Recife, 1991. Resumos. Recife: SEB, 1991. p.306.

PENMAN, D. R.; CHAPMAN, R. B.; BOWIE, M. H. Direct toxicity and repellent activity of pyrethroids against Tetranychus urticae (Acari: Tetranychidae). Journal of Economic Entomology, v.79, n.5, p.183-1187, 1986.

PENMAN, D. R.; CHAPMAN, R. B. Pesticide-induced mite outbreaks: pyrethroids and spider mites. Experimental and Applied Acarology, v.4, 265-276, 1988.

PLAPP, F. W. Jr.; BULL, D. L. Toxicity and selectivity of some insecticides to Chrysopa carnea, a predator of the tobacco budworm. Environmental Entomology, v.7, p.431-434, 1978.

POLETTI, M.; CAMPOS, F. J.; KONNO, R. H.; OMOTO, C. Predação de Amblyseius chiapensis Deleon (Acari: Phytoseiidae) sobre o ácaro-da-leprose dos citros In: SIMPÓSIO DE CONTROLE BIOLÓGICO, 7. Poços de Caldas, 2001. Resumos. Poços de Caldas: SEB, 2001. p.367. 
RAGA, A.; SATO, M. E.; CERÁVOLO, L. C.; ROSSI, A. C. Distribuição de ácaros predadores (Phytoseiidae) em laranjeiras (Citrus sinensis L. OSBECK). Ecossistema, v.21, p.23-5, 1996.

RAGA, A.; SATO, M. E.; CERÁVOLO, L. C.; ROSSI; A. C. Efeito de Halfenprox sobre Brevipalpus phoenicis (Geijskes) e ácaros predadores em citros. Revista de Agricultura, v.72, n. 3, p.363-373, 1997.

RASMY, A. H.; EL-BANHAWY, E. M. Biology and predatory eficience of two phytoseiid mites as affected by long-term pollen feeding. Entomophaga, v.20, p.93-95, 1975.

REIS, P. R. Aspectos bioecológicos e seletividade de agroquímicos a Iphiseiodes zuluagai Denmark \& Muma, 1972 (Acari: Phytoseiidae). Piracicaba, 1996. 154p. Tese (Doutorado) - Escola Superior de Agricultura "Luiz de Queiroz", Universidade de São Paulo.

REIS, P. R.; ALVES, E. B. Biologia de Euseius alatus Deleon (Acari: Phytoseiidae). Anais da Sociedade Entomológica do Brasil, v.26, n.2, p.359-363, 1997.

REIS, P. R.; SOUSA, E. O. Seletividade de chlorfenapyr e fenbutatin-oxide sobre duas espécies de ácaros predadores (Acari: Phytoseiidae) em citros. Revista Brasileira de Fruticultura., v.23, n. 3, p.584-588, 2001.

REIS, P. R.; CHIAVEGATO, L. G.; ALVES, E. B. Biologia de Iphiseiodes zuluagai Denmark \& Muma (Acari: Phytoseiidae). Anais da Sociedade Entomológica do Brasil, v.27, n.2, p.185-191, 1998a. 
REIS, P. R.; SOUSA, E. O.; ALVES, E. B. Seletividade de produtos fitossanitários ao ácaro predador Euseius alatus DeLeon (Acari: Phytoseiidae). Revista Brasileira de Fruticultura, v.21, n.3, p.350-355, 1999.

REIS, P. R.; TEODORO, A. V.; NETO, M. P. Predatory activity of Phytoseiidae mites on the developmental stages of coffee ringspot mite (Acari: Phytoseiidae: Tenuipalpidae). Anais da Sociedade Entomológica do Brasil, v.29, n.3, p.547-553, $2000 \mathrm{~b}$.

REIS, P. R.; CHIAVEGATO, L. G.; ALVES, E. B.; SOUSA, E. O. Ácaros da família Phytoseiidae associados à cultura dos citros no município de Lavras, Sul de Minas Gerais. Anais da Sociedade Entomológica do Brasil, v.29, n.1, p.435-441, 2000a.

REIS, P. R.; CHIAVEGATO, L. G.; MORAES, G. J.; ALVES, E. B.; SOUZA, E. O. Seletividade de agroquímicos ao ácaro predador Iphiseiodes zuluagai Denmark \& Muma (Acari: Phytoseiidae). Anais da Sociedade Entomológica do Brasil, v.27, n.2, p.265-274, 1998b.

RIELD, H.; HOYING, S. A. Toxicity and residual activity of fenvalerate to Typhlodromus occidentalis (Acari: Phytoseiidae) and its prey Tetranychus urticae (Acari: Tetranychidae) on pear. The Canadian Entomologist, v.115, p.807-813, 1983.

ROCK, G. C. Relative toxicity of two synthetics pyrethroids to a predator Amblyseius fallacis and its prey Tetranychus urticae. Journal of Economic Entomology, v.72, p.293-294, 1979.

RODRIGUES, J. C. V. Relações patógeno-vetor-planta no sistema leprose dos citros. Piracicaba, 2000. 168p. Tese (Doutorado) - Escola Superior de Agricultura "Luiz de Queiroz", Universidade de São Paulo. 
ROUSH, R. T.; HOY, M. A. Relative toxicity of permethrin to predator Metaseilus occidentalis and its prey Tetranychus urticae. Environmental Entomology, v.7, 287-288, 1978.

ROUSH, R. T.; HOY, M. A. Selection improves sevin resistance in spider mite predator. California Agriculture, v.34, n.1, p.11-14, 1980.

ROUSH, R. T.; HOY, M. A. Genetic Improvement of Metaseiulus occidentalis: selection with methomyl, dimethoate, and carbaryl and genetic analysis of carbaryl resistance. Journal of Economic Entomology, v.74, p.138-41, 1981a.

ROUSH, R. T.; HOY, M. A. Laboratory, glasshouse, and field studies of artificially selected carbaryl resistance in Metaseiulus occidentalis. Journal of Economic Entomology, v.74, n.2, p.142-47, 1981b.

ROUSH, R. T.; PLAPP, F. W. Biochemical genetics of resistance to carbaryl carbamates inseticides in the predaceous mite, Metaseiulus occidentalis. Journal of Economic Entomology, v.75, p.304-7, 1982.

SABELIS, M. W. The Phytoseiidae - capacity for population increase. In: HELLE, W.; SABELIS, M. W. (Ed.) Spider mites: their biology, natural enemies and control. Amsterdam: Elservier, 1985a. v.1B, p.35-41.

SABELIS, M. W. The Phytoseiidae - sex allocation. In: HELLE, W.; SABELIS, M. W. (Ed.) Spider mites: their biology, natural enemies and control. Amsterdam: Elservier, 1985b. v.1B, p.83-94.

SANDERSON, J. P.; MCMURTRY, J. A. Life history studies of the predaceous mite Phytoseius hawaiiensis. Entomologia Experimentalis et Applicata, v.35, p.227234, 1984. 
SANFORD, K. H. The influence of spray programs based on the fauna of apple orchards in Nova Scotia. XVII. Efects on some predacious mite. The Canadian Entomologist, n.99, p.197-201, 1967.

SANTOS, A. C.; GRAVENA, S. Seletividade de acaricidas à Pentilia egena Muls. (Col.: Coccinellidae) e ácaros predadores (Acari: Phytoseiidae) em cultura de citros. In: CONGRESSO BRASILEIRO DE ENTOMOLOGIA, 14. Piracicaba, 1993. Resumos. Piracicaba: SEB, 1993. p.591.

SANTOS, A. C.; GRAVENA, S. Eficiência de diflubenzuron para o ácaro da falsa ferrugem Phyllocoptruta oleivora (Ash.) (Acari: Eriphyidae) e seletividade a Pentilia egena (Muls.) (Coleoptera: Coccinellidae) e ácaros predadores. Anais da Sociedade Entomológica do Brasil, v.24, n.2, p. 345-351, 1995.

SANTOS, A. C.; GRAVENA, S. Seletividade de acaricidas a insetos e ácaros predadores em citros. Anais da Sociedade Entomológica do Brasil, v.26, n.1, p.99-105, 1997.

SATO, M. E.; MIYATA, T.; KAWAI, A.; NAKANO, O. Selection for resistance and susceptibility to methidathion and cross resistance in Amblyseius womersleyi Schicha (Acari: Phytoseiidae). Applied Entomology and Zoology, v.35, n.3, p.393-399, 2000 .

SATO, M. E.; RAGA, A.; CERÁVOLO, L.C.; ROSSI, A. C.; CEZÁRIO, A. C. Efeito de acaricidas sobre Brevipalpus phoenicis (Geijskes, 1939) (Acari: Tenuipalpidae) e ácaros predadores (Família Phytoseiidae) em citros. Revista Brasileira de Fruticultura, v.14, n.2, p.87-93, 1992. 
SATO, M. E.; RAGA, A.; CERÁVOLO, L.C.; ROSSI, A. C.; CEZÁRIO, A. C. Efeito da utilização de acaricidas em citros, sobre a população de Brevipalpus phoenicis (Geijskes, 1939) (Acari: Tenuipalpidae) e ácaros predadores (Família Phytoseiidae). Scientia Agricola, v.52, n.2, p.282-286, 1995.

SATO, M. E.; RAGA, A.; CERÁVOLO, L.C.; ROSSI, A. C.; POTENZA, M. R. Ácaros predadores em pomar cítrico de Presidente Prudente, estado de São Paulo. Anais da Sociedade Entomológica do Brasil, v.23, n.3, p.435-441, 1994.

SATO, M. E.; RAGA, A.; CERÁVOLO, L.C.; ROSSI, A. C.; SOUZA FILHO, M. F. de. Toxicidade residual de acaricidas a Iphieiodes zuluagai Denmark \& Muma, 1972 (Acari: Phytoseiidae). Arquivos do Instituto Biológico, v.63, n.1, p.15-19, 1996.

SCHULTEN, G. G. M. Pseudo-arrhenotoky. In: HELLE, W.; SABELIS, M. W. (Ed.) Spider mites: their biology, natural enemies and control. Amsterdam: Elservier, 1985. v.1B, p.67-71.

SILVA, L. M. Efeito de produtos químicos e do fungo Hirsutella thompsoni (Fischer, 1950) no ácaro da falsa ferrugem Phyllocoptruta oleivora (Ashmead, 1879) e no ácaro predador Iphiseiodes quadripilis (Banks, 1950) em citros. Jaboticabal, 1980. 74p. Dissertação (Mestrado) - Faculdade de Ciências Agrárias e Veterinárias, Universidade Estadual Paulista "Júlio de Mesquita Filho".

SOLOMON, M. G.; EASTERBROOK, M. A.; FITZGERALD, J. D. Mite-management programmes based on organophosphate-resistant Typhlodromus pyri in UK apple orchards. Crop Protection, v.12, n.4, p.249-254, 1993.

STRICKLER, K.; CROFT, B. A. Variations in permethrin and azimphosmethyl resistance in populations of Amblyseius fallacis (Acarina: Phytoseiidae). Environmental Entomology, v.10, n.2, p.233-236, 1981. 
STRICKLER, K.; CROFT, B. A. Selection for permethrin resistance in the predatory mite, Amblyseius fallacis. Entomologia Experimentalis et Applicata, v.31, p.339$345,1982$.

SUÁREZ, A. E. F.; BRECEDA, S. F.; BADII, M. H.; ORTIZ, E. H. Efecto del dicofol en la oviposicion y parametros reproductivos de Euseius mesembrinus (Acari: Phytoseiidae). Agrociencia, v.31, n.2, p.203-207, 1997.

TANIGOSHI, L. K.; CONGDON, B. D. Laboratory toxicity of commonly-used pesticides in California citriculture to Euseius hibisci (Chant) (Acarina: Phytoseiidae) Journal of Economic Entomology, v.76, p.247-250, 1983.

THISTLEWOOD, H. M. A. A survey of predatory mites in Ontario apple orchards with diverse pesticide programs. The Canadian Entomologist, v.123, p.1163-1174, 1991.

THISTLEWOOD, H. M. A.; PREE; D. J.; CRAWFORD, L. A. Comparasion of slid dip and petri dish assays for measuring resistance to permethrin in Amblyseius fallacis (Acari: Phytoseiidae). Journal of Economic Entomology, v.85, p.2051-2057, 1992.

THISTLEWOOD, H. M. A.; PREE; D. J.; CRAWFORD, L. A. Selection and genetic analyses of permethrin resistance in Amblyseius fallacis (Garman) (Acari: Phytoseiidae) from Ontario apple orchards. Experimental and Applied Acarology, v.19, p.707-721, 1995.

VAN DE VRIE, M. Apple. In: HELLE, W.; SABELIS, M. W. (Ed.) Spider mites: their biology, natural enemies and control. Amsterdam: Elservier, 1985. v.1B, p.311-325. 
WHALON, M. E.; CROFT, B. A. Introduction and survival of susceptible and pyrethroid-resistant strains of Amblyseius fallacis (Acari: Phytoseiidae) in a Michigan apple orchard. Environmental Entomology, v.11, n.5, p.1096-1099, 1982.

WRIGHT, D. J.; VERKERK, R. H. J. Integration of chemical and biological control systems for arthropods: evaluation in a multitrophic context. Pesticide Science, v.44, p. 207-218, 1995.

YAMAMOTO, P.T.; GRAVENA. S. Influência da temperatura e fontes de alimento no desenvolvimento e oviposição de Iphiseiodes zuluagai Denmark \& Muma (Acari: Phytoseiidae). Anais da Sociedade Entomológica do Brasil., v.25, n.1, p.109-115, 1996.

YAMAMOTO, P.T.; PINTO, A. S.; PAIVA, P. E. B.; GRAVENA. S. Seletividade de agrotóxicos aos inimigos naturais de pragas dos citros. Laranja, v.13, n.2, p.709$755,1992$.

YANINEK, J.S.; MORAES, G.J. de. A synopsis of classical biological control of mites in agriculture. In: DUSBABECK, F.; BUKVA, V. (Ed.), Modern acarology. Prague: Academia, 1991. p.133-149.

ZHAO, Z.; McMURTRY, J. A. Development and reproduction of there Euseius (Acari:Phytoseiidae) species in the presence and absence of supplementary foods. Experimental and Applied Acarology, v.8, p.233-242, 1990. 